\title{
Morphological growth pattern of Phanerochaete chrysosporium cultivated on different Miscanthus X giganteus biomass fractions
}

\author{
Hassan KHALIL \\ CentraleSupelec \\ Estelle LEGIN \\ Universite de Reims Champagne-Ardenne
}

\section{Bernard KUREK}

INRAE

\section{Patrick PERRE}

CentraleSupelec

Behnam TAIDI ( $\sim$ behnam.taidi@centralesupelec.fr)

CentraleSupelec https://orcid.org/0000-0001-7721-1314

\section{Research}

Keywords: Miscanthus x giganteus, solid-state fermentation, Phanerochaete chrysosporium, microscopy and image processing, spore germination, mycelial growth

Posted Date: July 15th, 2020

DOI: https://doi.org/10.21203/rs.3.rs-42651/v1

License: (a) (i) This work is licensed under a Creative Commons Attribution 4.0 International License. Read Full License

Version of Record: A version of this preprint was published at BMC Microbiology on November 17th, 2021. See the published version at https://doi.org/10.1186/s12866-021-02350-8. 


\section{Abstract}

The growth pattern of Phanerochaete chrysosporium on different Miscanthus $x$ giganteus biomass fractions was investigated via an original method based on microscopy and image processing. The growth medium, together with image acquisition, was designed to study the mycelia growth non-invasively. Object coalescence, the colonized surface area, and radial expansion of the colony were measured. The substrate was sterilized by autoclaving, which could be considered a pre-treatment. The fastest growth rate was measured on the entire biomass, followed by the soluble fraction of the biomass, and finally, the residual solid fraction of the substrate pre-treated by autoclave. The growth rate on the different fractions of the substrate was additive, suggesting that both the solid and liquid fractions were used by the fungus, although the solid fraction of the substrate seemed to provide a richer but less accessible nutritional source. Based on the FTIR analysis, there were differences in composition between the solid and soluble fractions of the substrate, but the main components for growth were always present. We propose using this novel method for measuring initial fungal growth by following the variation of the number of objects over time. The methodology may be applied to the examination of other filamentous fungi.

\section{Introduction}

Fungal solid-state fermentation (SSF) is an aerobic culture system in which filamentous fungi are grown on the surface of and/or within substrate biomass, with adequate water activity and a sufficiently open network that allows air penetration (Gowthaman, Krishna, and Moo-Young 2001). Examples of industrial applications of SSF include pre-treatment of agricultural by-products to produce simple sugars (e.g., glucose and xylose) (Khullar et al. 2013), enzymes (e.g., cellulases, xylanases, ligninases) (Urek and Pazarlioglu 2007; Graminha et al. 2008), organic acids (e.g., citric acid) (Kumar et al. 2003), pigments (Velmurugan et al. 2011), flavors (Soares et al. 2000), and fine chemicals. In the food industry, SSF is used to manufacture food additives and to produce fermented foods such as ripened cheese (e.g., Roquefort) (Ropars et al. 2017) and fermented rice (e.g., tapé, tempeh) (Cook et al. 1991; Reyes-Moreno et al. 2000) and even to grow edible mushrooms (e.g., Agaricus bisporus) (de Andrade et al. 2008). More recently, SSF has been proposed for the potential biodegradation of hazardous compounds (e.g., polychlorinated biphenyls [PCBs]) (Ruiz-Aguilar et al. 2002), the bioremediation of nitrocellulose pollution (Auer, Veness, et Evans 1999; Gladchenko et al. 2015), and for the detoxification of agro-industrial waste (e.g., coffee pulp) (Londoño-Hernandez et al. 2020).

In natural ecosystems, filamentous fungi degrade the lignocellulosic biomass that is otherwise difficult to decompose. Lignin, cellulose, and hemicelluloses are the major polymeric constituents of lignocellulosic materials (Bajpai 2016), such as hardwoods, softwoods, and non-woody plants (Ververis et al. 2004). It is well known that lignocellulosic biomass can be used as a potential feedstock in biorefinery operations (Konwar et al. 2018). Among those biomass sources is Miscanthus $x$ giganteus (hereafter referred to as miscanthus), a rhizomatous perennial grass (Heaton 2004; Anderson et al. 2011), with a high cellulose content $(>40 \% \mathrm{w} / \mathrm{w})$ in its stalks and branches (Ververis et al. 2004). This plant is an excellent candidate to provide lignocellulosic bioenergy due to its low nutrient requirements and high productivity (Roni et al. 2016; Qin et al. 2011). According to France Miscanthus (www.france-miscanthus.org), the total cultivated surface of miscanthus in France was greater than 6000 ha in 2019, with a 10\% annual increase in recent years 
(France Miscanthus 2020). The dry matter yields in France are 15 to 40 tonnes/ha (Qin et al. 2011), which can be turned into combustible solid (pellets) (Samson et al. 2018) or used as a lignocellulosic substrate to produce second-generation liquid fuels through fermentation of its high cellulose content (Lee and Kuan 2015; Vasco-Correa et al. 2016; Dubis et al. 2017; Vasco-Correa and Shah 2019).

Among the three main groups of wood rot fungi (white, brown, and soft rot-fungi), white-rot fungi are capable of efficiently mineralizing lignin, and cellulose and hemicelluloses in woody biomass (Mester et al. 2004). These three groups of fungi occupy different ecological niches, such as deciduous trees, agricultural crops, and plant roots (Rytioja et al. 2014). Phanerochaete chrysosporium is a white-rot fungus, used frequently as an experimental organism. Its genome has been fully sequenced (Martinez et al. 2004). Its lignocellulolytic system has been extensively studied, which has led to the delineation of the main complex mechanisms of the plant biomass degradation processes (Broda 1993; Adav et al. 2012; Kameshwar and Qin 2017).

Phanerochaete chrysosporium quickly colonizes wood, degrading the lignin but often leaving cellulose almost unaffected ( Srebotnik et al. 1988; Eriksson et al. 1990; Kersten and Cullen 2007; Oliveira et al. 2010). The fungus excretes multiple lignin and manganese peroxidases (LiPs and MnPs) to mineralize lignin, the most recalcitrant component in lignocellulosic biomass (Kersten and Cullen 2007). The ligninolytic activities occur principally after the primary growth phase, once nutrient-limitation is encountered by the organism (Ruel et al. 1994). The regulation and the expression of $P$. chrysosporium genes encoding ligninolytic enzymes have been reported on wood and defined medium (rich/poor medium in nitrogen/carbon) (Janse et al. 1998; Sato et al. 2007; Vanden Wymelenberg et al. 2010). The fungus can efficiently depolymerize polysaccharides in plant biomass by using a battery of hydrolytic enzymes (Pérez et al. 2002). The $P$. chrysosporium genome contains a vast repertoire of cellulose/hemicellulose polysaccharide-degrading enzymes ( Martinez et al. 2004; Rytioja et al. 2014). The cellulolytic-enzymes are constitutive and continue to be produced during the different phases of fungal growth and degradation of lignocellulosic biomass (Ray et al. 2012). Among 35 fungal species studied for miscanthus degradation, $P$. chrysosporium showed the greatest degrading activity, with approximately $20 \%$ of biomass weight loss after eight weeks (Shrestha et al. 2015).

The robustness of the SSF process, including the colonization of the substrate by the desired microorganisms, is a major technological issue (Gowthaman et al. 2001; Soccol et al. 2017). Spore inocula offer high repeatability in the cultivation process (Krishna and Nokes 2001). Generally, a sufficient concentration of spores allows for the rapid proliferation of fungal biomass, guarantees a significant production of metabolites, and reduces the risk of contamination (Jha et al. 1995). Thus, the ability to monitor inoculation, germination, and initial growth is a prerequisite for accurate process control and efficient conversion of lignocellulosic substrate into desired products.

Measuring the growth of filamentous fungi is challenged by practical difficulties. The mycelium becomes attached to the substrate and could penetrate deeply, complicating any attempts to recover it and, therefore, to determine the fungal biomass by weight. Direct measurement of growth is impossible, and various microscopic techniques are used to quantify relative growth and morphology. Field emission gun scanning electron microscopy (FEGSEM) is a 3D ultrastructural approach for characterizing the size and shape of spores and the morphology of filaments in solid systems. Despite the large depth of field offered by this 
method, it relies on destructive fixation and dehydration, resulting in the inactivation of living samples, preventing continuous observation over time (De Almeida et al. 2017). Laser scanning confocal microscopy (LSCM), a non-destructive 3D observation method, has been used for morphological characterization and quantification of mycelial growth (Du et al. 2016). The advantage of this technique is the level of detail of obtained data, but the use of fluorochromes to visualize the mycelial biomass weakens the approach.

In 2D observations, specific key data are inaccessible, such as tip extension rate, branch angle, branching length distribution, hyphal fusion, and the volume of fungal biomass as a number of voxels. For 3D highresolution observation, the very slow point-by-point scanning rates result in long acquisition times that are not only inconvenient but even impossible to apply without influencing the growth of the organism. Using dyes for reducing scan time or increasing resolution can also affect the organism under study (Czymmek and Whallon 1994).

Non-destructive 2D observation of filamentous fungi in Petri dish cultures can be performed using a flat-bed scanner but resulting in low-resolution images (De Ligne et al. 2019). Spore germination and mycelium formation of Penicillium expansum and Aspergillus niger have been observed on agar for extended periods using time-lapse photography (Gougouli and Koutsoumanis 2013). Researchers have often monitored the growth of one mycelial colony originating from the germination of single spore without accounting for the realistic event in SSF in which a large population of spores is inoculated into the substrate (Barry et al. 2007; Barry et al. 2015; Vidal-Diez de Ulzurrun et al. 2019). Experimental data reported (Gougouli and Koutsoumanis 2013) heterogeneous germination times for individual spores even though they were all treated under the same conditions. This heterogeneity can be corrected for by following a large number of spores. The larger the population the more realistic woud be the observation. Data on the behavior of a large number of colonies originating from single spores during the colonization of a natural substrate is still lacking.

Image analysis has been used to study the impact of environmental conditions on the growth of filamentous fungi at different stages. Some studies examined the germination of spores, others the growth dynamics starting from a mycelia fragment, and rarely from germination to mycelium development (Nanguy et al. 2010; Gougouli and Koutsoumanis 2013; Du et al. 2016; De Ligne et al. 2019). Generally, the primary focus has been on temperature, relative humidity, aeration, synthetic substrate composition, and/or nutrient concentration (Hassouni and Ismaili-Alaoui 2007; Gougouli and Koutsoumanis 2013; De Ligne et al. 2019). To our knowledge, all the techniques used to follow growth on a natural substrate are destructive with two notable exceptions based on the same technique: stereomicroscopy with time-lapse digital imaging was used to follow Aspergillus niger mycelial growth on wheat straw (Couri and Merces 2006; Dutra et al. 2008) .

The first hours of fermentation on solid substrate determine the future success of the culture (Sekiguchi and Gaucher 1977; Manan and Webb 2017). In non-axenic SSF, other microorganisms (such as bacteria) besides the fungus could invade the medium (Raimbault 1998; Chen 2013). These organisms can lower process productivity and specific metabolite production if their growth is faster than that of the selected fungus (Lonsane et al. 1992; Chen 2013), so the desired species must outcompete other species that may be present. 
The timely germination of fungal spores, the rapid elongation of the germ tubes, and the generation of new branches are the principal factors in the successful development of mycelium in SSF. The present study aims to explore the germination and growth characteristics of $P$. chrysosporium on a natural substrate during the first 52 hours of fermentation. An experimental system was developed to investigate the growth characteristics of $P$. chrysosporium on different fractions of miscanthus non-invasively. How $P$. chrysosporium consumes the different components (soluble and solid) of miscanthus was monitored and provided insight into the way this organism attacks its substrate.

\section{Materials \& Methods}

\section{Materials}

Miscanthus $x$ giganteus (shredded stems received harvested at the end of March 2017 near Rethel in France; Agromi S.A.S) was used as a lignocellulosic substrate. The $\mathrm{C} / \mathrm{N}(\mathrm{w} / \mathrm{w})$ ratio was 100:1 (supplier information) with a moisture content of $15 \%(\mathrm{w} / \mathrm{w})$, determined by halogen lamp moisture analyzer OHAUS ${ }^{\mathrm{Tm}} \mathrm{MB}-45$. The stems were milled sequentially to $1 \mathrm{~mm}$ (Retsch Cross Beater Mill SK1) and sifted through sieves of mesh sizes $4 \mathrm{~mm}, 2 \mathrm{~mm}$, and $1 \mathrm{~mm}$. The particles were pulverized first to $200 \mu \mathrm{m}$ and then to $80 \mu \mathrm{m}$ (Ultra Centrifugal Mill ZM 200; Retsch ${ }^{\circledR}$ ). Ring sieve cassettes with 0.2- and 0.08-mm conical holes were used for this purpose. The $80 \mu \mathrm{m}$ particles were subsequently selected for the experiments.

Phanerochaete chrysosporium (BRFM 531) was obtained from the CIRM-INRAE collection (https://www6.inrae.fr/cirm/) in sterile glycerol solution (10\% v/v) and stored at $4{ }^{\circ} \mathrm{C}$.

Agar Sigma@ (Sigma-Aldrich A1296 Lot \# BCBR4069V) was included in all solid growth media before pouring the molten preparations in Petri dishes (Thermo Scientific ${ }^{\mathrm{TM}}$ Sterilin $^{\mathrm{Tm}} \varnothing=55 \mathrm{~mm}$; ht. $=12 \mathrm{~mm}$ ). Inverted grey gridded cellulose nitrate membrane filters (Sartorius ${ }^{\mathrm{TM}} 13006-47-\mathrm{ACN}, \varnothing=47 \mathrm{~mm}$; pore size: $0.45 \mu \mathrm{m}$ ) were used as support for the spore suspension and subsequent growth of $P$. chrysosporium.

Zeiss Microscope (Axioplan 2, Carl Zeiss Microscopy GmbH, Germany) Imaging was used with a Malassez counting chamber for estimation of spore concentration in suspensions. Observations of growth in all experiments were performed using an automated microscope (Carl Zeiss Axio Zoom V.16, GmbH, Germany).

\section{Inoculum preparation}

Phanerochaete chrysosporium was grown in Petri dish culture on MAE medium containing (w/v): malt extract (2\%) (Sigma-Aldrich 70167 Lot \# BCBR6119V) and agar (2\%) (Sigma-Aldrich A1296 Lot \# BCBR4069V). The strain was kept in perpetual culture with twice weekly sub-culturing on solid media.

To prepare a spore suspension, a fragment $(5 \mathrm{~mm} \varnothing)$ of mycelial growth was cut from the margin of an actively growing colony and incubated on fresh growth medium at $25^{\circ} \mathrm{C}$ for 14 days. The spores of $P$. chrysosporium were detached and harvested by using seven sterile glass beads and sterile Milli-Q water $(5 \mathrm{ml})$ containing $0.2 \%(\mathrm{v} / \mathrm{v})$ Tween 80 detergent. The conidial suspension was recovered, and the spore density was estimated by microscopy. The suspension was diluted with sterile Milli-Q water to a concentration of 100 conidia $\mu \mathrm{l}^{-1}$ and stored for $67 \pm 2$ hours at $4{ }^{\circ} \mathrm{C}$. 


\section{Experimental procedure for growth on fractionated biomass}

Miscanthus was sterilized at $121^{\circ} \mathrm{C}$ for $20 \mathrm{~min}$ (which also acted as a hydrothermal pre-treatment of the biomass), followed by tempered at $70^{\circ} \mathrm{C}$ for $15 \mathrm{~min}$ in a water bath. The growth media were prepared using agar containing the pre-treated unfractionated substrate (miscanthus; $80 \mu \mathrm{m}$ ) or its fractions (Fig. 1). All agar gels were covered with a filter membrane that was used as a support for the growth of the mycelium. Growth of $P$. chrysosporium was monitored on duplicate cultures on five different culture media. All cultures were incubated at $25^{\circ} \mathrm{C}$.

Figure 1. Experimental apparatus and procedure. Phase (I) shows the preparation of all growth media. Phase (II) demonstrates the experimental device. The grey nitrocellulose membrane was placed, grid side down, on the surface of the agar containing different substrates to hide the white lines and provide a homogeneous background for imagery. The preparations were tempered to $70{ }^{\circ} \mathrm{C}$.

\section{i. Non fractionated (B) and control (A) substrates}

The agar was included primarily to provide moisture during incubation. The negative control (culture A) contained only agar $(2 \% \mathrm{w} / \mathrm{v})$, on which no fungal growth was expected.

The non-fractionated substrate, used for culture B, contained miscanthus (4 g), agar (4 g), and Milli-Q water $(200 \mathrm{ml})$ (Fig. 1). After sterilization, $15 \mathrm{ml}$ of well-mixed medium were poured into each Petri dish $(55 \mathrm{~mm}$ diameter) and allowed to solidify (Fig. 1). This culture was included to provide a reference point for the natural growth of the organism.

\section{ii. Fractionated substrates}

Miscanthus (4 g) and agar (4 g) were autoclaved separately in Milli-Q water (200 ml each). Using the former suspension, the soluble and solid fractions were separated by sterile filtration under vacuum (Fig. 1). The filtrate (substrate $\mathrm{C}$ ) was mixed with an equal volume of agar solution and poured into the Petri dish. This substrate was used for the growth of culture $C$ that contained the "soluble miscanthus fraction." The solid portions were added into an agar solution $(200 \mathrm{ml})$ and dispensed $(15 \mathrm{ml})$ into Petri dishes. The substrate designated as "unwashed solid fraction" consisted of solid particles that remained on the filter after simple filtration of the autoclaved miscanthus suspension. This fraction was used for culture $D$. In a separate preparation, the solid fraction obtained after filtration was washed with sterile Milli-Q water $(1 \mathrm{~L})$ to form the "washed solid fraction," which after addition into the agar solution was called substrate $E$ and was used for culture E (Table 1). 
Table 1

Culture media and respective substrates used; corresponding denomination relative to FTIR analysis.

\begin{tabular}{|lll|}
\hline Culture & $\begin{array}{l}\text { Substrate type and designation } \\
\text { A }\end{array}$ & $\begin{array}{l}\text { Identification of the freeze-dried substrate analyzed by } \\
\text { FTIR }\end{array}$ \\
\hline B & No lignocellulosic biomass & - \\
& Non-Fractionated Substrate & FTIR-B \\
& & \\
C & Substrate B & \\
\hline D & Soluble Fraction - substrate C & FTIR-C \\
& Substrate D & FTIR-D \\
\hline E & Washed Solid Fraction - substrate & FTIR-E \\
\hline
\end{tabular}

\section{iii. Experimental system and culture procedure}

A drop of spore suspension $(10 \mu \mathrm{l})$ was deposited onto the center of the filter. After ten minutes (the time for the drop to be absorbed into the paper), the plates were sealed and observed by microscope (designated time $0)$. All cultures were prepared and incubated in duplicate. The average data value is presented in results.

\section{Microscopy}

Growth was monitored using a 50X/3.3 REO objective lens and a Hamamatsu Camera. The unopened Petri dish was placed on a motorized stage (with X-Y coordinates). A brightfield configuration with a bespoke image acquisition process (ZEN blue edition software) was used with 100\% illumination (300 ms per tile). The number of tiles used for imaging was chosen depending on the size of the entire colony. The overlap between two neighboring tiles was $10 \%$. The one-pixel size was equivalent to $1.3 \mu \mathrm{m}$, and the depth of focus was $15.6 \mu \mathrm{m}$.

\section{Image processing and measurements}

Composed images were exported in TIFF format and processed using Image ${ }^{\mathrm{TM}}$. Overlap was eliminated, and images were reassembled with the "Grid/Collection stitching" plugin (Preibisch, Saalfeld, and Tomancak 2009). The median filter was used to minimize the variation in the grey values of image pixels within a specific neighborhood. The "Enhance Local Contrast (CLAHE)" was used to enhance the local contrast. The unevenly illuminated background was corrected by the "subtract background" command. Image processing continued using a combination of median, mean, and maxi filters to improve the processing and reduce noise. Finally, the 8-bit image was converted to a binary image. "Yen thresholding" was used for binarization of images acquired at time 0 , whereas the "Otsu threshold" method was applied for all subsequent images. The image toolbox of Matlab measured colony diameter, the area occupied by the mycelium, the total 
number of objects (spores and later, independent networks), and their areas. The spores and colonies (germ tubes, mycelia generated from individual spores, mycelium resulting from the 2D visual connection of many mycelia) are supposed to appear as discrete objects in binary images. As the stage holding the specimen was adapted to move in both $X$ and $Y$ directions only, the measurements were performed pixel by pixel on the surface.

\section{Elemental analysis}

The samples to be analyzed were lyophilized ( $4.10^{-5}$ bar pressure for 72 hours), and $1 \mathrm{mg}$ duplicates were used. The elemental ( $\mathrm{C}, \mathrm{H}, \mathrm{N}, \mathrm{S}$, and $\mathrm{O})$ composition was determined for milled miscanthus biomass, agar powder, and the nitrocellulose membrane using a CHNS-O analyzer (Thermo Scientific Flash 2000 Organic Elemental Analyzer, USA) and the "Eager Xperience" software(Thermo Scientific).

\section{Description of FTIR (Fourier transform infrared) sample analysis}

All substrates (B to E) were lyophilized before preparing the samples for FTIR-analysis (Fig. 1; Table 1).

In addition to the substrate fractions, FTIR was used to analyze the "FTIR-Ew" samples obtained by the lyophilization of the wash-water recovered from washing substrate D (Fig. 1; Table 1).

\section{Sample conditioning and FTIR acquisition}

Lyophilized dry matter $(2.4 \mathrm{mg}$ ) was mixed and ground with $200 \mathrm{mg} \mathrm{KBr}$ to form disk samples. The spectra of all samples were collected in transmittance mode by the FTIR spectrometer (Thermo Fisher Nicolet, 6700 FTIR). All spectra were acquired from 4000 to $400 \mathrm{~cm}^{-1}$ at $4 \mathrm{~cm}^{1}$ intervals, and the absorbances measured were averaged over 16 scans and corrected by background-air subtraction. The individual spectra were corrected for their baselines and normalized to the same total area using "OMNIC" (Thermo Fisher) version 8 software. The intensity of the absorption characteristic for each functional group of interest was then determined as the height of the signal at the relevant wavenumber. For data recovery, SpectraGryph v1.2.12 software (Germany) was used.

\section{Results}

The miscanthus biomass was sterilized by autoclaving, which constituted a hydrothermal pre-treatment resulting in the extraction of soluble products into the water phase of the autoclaved samples. From this pretreated material, several fractions were separated and incorporated into different agar Petri dishes.

The growth of $P$. chrysosporium on solid media containing different fractions of miscanthus was followed by non-destructive microscopic observation. Two cultures were used as reference cultures: culture $A$ which was devoid of any added miscanthus and culture B that incorporated the whole non-fractionated miscanthus. Culture A consisted of medium A containing only agar and the superimposed nitrocellulose membrane. The experiment was terminated for all the cultures when the fastest-growing culture started to reach the maximal image size (24 $\mathrm{mm}$ wide). 
The experimental apparatus and data processing methods allowed for successive observation of $P$. chrysosporium growth on the different miscanthus biomass fractions incorporated in agar. An example of the image produced from a $52 \mathrm{~h}$ growth of $P$. chrysosporium on agar medium without any fraction of miscanthus is shown in Fig. 2. The left image is composed of 25 single overlapping images (tiles). The tiles were separated and reassembled into one image. Images with good black/white contrast were obtained, allowing for accurate quantification of the surface occupied by the fungus. Growth measurements (occupied area, colony diameter, germination rate, the number of objects) were determined from the processed images.

Figure 2. Example of acquired and processed images of a P. chrysosporium colony. The image acquired after 52 hours of growth on agar medium is on the left. The processed image after image treatment operations (as described in the text) is on the right. Red scale bar $=2000 \mu \mathrm{m}$.

The spores were visualized during the early stages of growth (Figs. 3 \& 4). The number of spores decreased over time as the spores germinated, and the germ tubes grew into hyphae. The germination rate was determined between 0 and 23 hours. The mycelium developed on the surface through tip extension and branching, leading to an interconnected mycelial network and the formation of a colony that grew radially over time (Figs. 3 \& 4 red circles).

Figure 3. Germination and growth of P. chrysosporium on agar (defined as negative control - substrate A). Monitoring was performed at 50X magnification. Images show the growth at time $0,23,26,29,46.5,49.5$, and 52 hours. A scale-shift of the image is indicated by the change in the color of the drawn squares from red to blue. The sides of the red square measure $9000 \mu \mathrm{m}$. The length of the sides of the blue squares was $11000 \mu \mathrm{m}$, and the image size is 12288-pixel x 12288-pixel. The red circles show the position of a single spore over time. At 23 hours, the spore was swollen. At 26 hours, a germ tube was formed. A microcolony was observed at 29 hours, where branching started. The final colony can be seen at 52 hours. The red scale bars measure $2000 \mu \mathrm{m}$.

The fungi growth on the nitrocellulose membrane placed on agar devoid of any miscanthus fraction (culture A) was relatively slow (Fig. 3). The final size of the colony reached $3.9 \times 10^{7} \mu \mathrm{m}^{2}$. The fastest growth (Fig. 4) was observed when non-fractionated miscanthus was incorporated into the agar (culture B). The size of the colony at $52 \mathrm{~h}$ was $3.2 \times 10^{8} \mu \mathrm{m}^{2}$, eight times greater than culture $\mathrm{A}$.

Figure 4. Germination and growth of P. chrysosporium on the non-fractionated substrate (culture B). The monitoring was performed at 50X magnification. Images show the growth at time $0,23,26,29,46.5,49.5$ and 52 hours. The color change of the square drawn around the colony from red to purple indicates a change in the scale of the image. The sides of the red square measure $9000 \mu \mathrm{m}$. The sides of the purple squares are $25000 \mu \mathrm{m}$ long, and the image size is 24576-pixel x 24576-pixel. The red circles show the position of a single spore over time. At 23 hours, the spore was swollen, and a germ tube was formed. At 26 hours, a microcolony was obtained where branching start to take place. At 29 hours, the amplification of branching continued, and the tips extended, forming bridges with other microcolonies. One colony can be seen at 46.5 hours. The red scale bars measure $2000 \mu \mathrm{m}$. 
The spore germination percentage and the calculated spore germination rate for the two cultures (Table 2) showed a large difference in their initial growth rates. Culture B, containing the substrate, grew much more rapidly. The percentage of spore germination was significantly greater in culture $B$, which was reflected in the spore germination rate. The only apparent inconsistency in these observations was in culture A, wherein the germination rate was greater between 23 and 26 hours. This observation must be interpreted by considering that the majority of the spore population germinated during this time in culture $\mathrm{A}$.

Table 2

The percentage of germinated spores during the first 29 hours. All objects observed at time $0 \mathrm{~h}$ were considered to be spores. The average size of these objects was $560 \mu \mathrm{m}^{2}$.

\begin{tabular}{|llllllll|}
\hline & \multicolumn{6}{c}{ Spore germination percentage } & \multicolumn{3}{c|}{ Spore germination rate (spore/h) } \\
\hline \multirow{3}{*}{ Substrate } & Time (h) & $\mathbf{2 3}$ & $\mathbf{2 6}$ & $\mathbf{2 9}$ & $\mathbf{2 3}$ & $\mathbf{2 6}$ & $\mathbf{2 9}$ \\
\cline { 2 - 7 } & A & 17 & 64 & 89 & 5 & 110 & 60 \\
\cline { 2 - 7 } & B & 78 & 90 & 94 & 23 & 28 & 11 \\
\hline C & 66 & 90 & 96 & 19 & 51 & 13 \\
\hline D & 64 & 93 & 97 & 18 & 65 & 7 \\
\hline E & 14 & 72 & 81 & 4 & 126 & 18 \\
\hline
\end{tabular}

The deposition of the inoculum droplet containing spores left a marked area on the nitrocellulose membrane, corresponding to the maximum area where germination would first occur. Even after complete absorption of the droplet into the paper, this mark persisted. Colonization of the membrane surface in all experiments occurred first within this marked area. It was noted that the spores near the edge of the mark showed a tendency to first grow inwards rather than outside of the marked area.

Comparative extent of P. chrysosporium growth on substrate fractions

\section{Growth as measured by spore germination rate}

Observing the percentage spores' germination, culture $\mathrm{A}$ and culture $\mathrm{E}$ demonstrated very similar results (Table 2). The growth rate measured in this way was very similar for cultures $B, C$, and D. The final spore germination percentage was very high for all cultures (81-87\%), demonstrating good spore viability. Culture B gave a slight but significantly higher growth rate as measured by this method (Table 2).

Figure 5. The area occupied by P. chrysosporium mycelia after $\mathbf{5 2}$ hours. The blue and orange bars indicate the data of duplicate cultures for each substrate. The corresponding images visually represent the growth and morphology of the colonies at each time point. The upper row of images corresponds to the data represented by the blue bars, and the lower images correspond to the data represented by the orange bars. Each side of the purple square is $25000 \mu \mathrm{m}$. The mycelium in culture B covered $3.0 \pm 0.2 \times 10^{8} \mu \mathrm{m}^{2}, 8$-fold higher than the negative control (culture $A$ ). At the same time point, culture $C$ was $78 \%$ of culture $B$; culture $D$ was $42 \%$ of culture $B$, and culture $E$ was $26 \%$ of culture B. The use of non-fractionated miscanthus (Fig. 1) 
resulted in the fastest growth of the organism followed by the soluble fraction (culture $\mathrm{C}$ ), the unwashed solid fraction (culture $D$ ), and the washed solid fraction (culture $E$ ). If the growth area on agar alone (culture $A$ ) is subtracted from all growth data, the sum of the growth measured on cultures $C$ and $D$ provided a value close to that of culture B. Thus, the covered area on culture $C$ at 52 hours represented $64 \%$ of the covered area of culture $B$; the soluble fraction is largely responsible for the extent of mycelial growth.

\section{Growth rates as measured by particle coalescence}

At time zero, all objects were considered to be spores. Coalescence was defined as the rate at which the number of objects decreased. The objects consisting of spores and microcolonies (germ tubes and mycelia) were counted at each time point. The variation in the number of objects demonstrated a rapid growth measurement in the early stages of colony development.

The coalescence dynamics were followed for the first $29 \mathrm{~h}$ of incubation, after which time it was no longer possible to follow the number of individual objects. The decline in the number of objects accelerated after 26 hours, even with the washed solid fraction (Fig. 6 III). The change in the number of objects correlated well with the average size of counted objects (Table 4). At 29 hours, the percentage of objects remaining from the initial spores was $85,30,18,60$, and $80 \%$ on cultures $A, B, C, D$, and $E$, respectively. Thus, the fastest growth was observed in culture $\mathrm{C}$, and cultures $\mathrm{A}$ and $\mathrm{E}$ demonstrated very similar growth rates.

\section{Growth rates as measured by radial extension}

Once complete coalescence had occurred, the mycelial mat could be considered a single colony. The radial extension of the colony was the internal distance between the circumferences of each colony.

Due to the observation that initial growth took place within the marked area where the spores were deposited, no radial growth was observed during the first 29 hours. After this period, the colony diameters for cultures B and $C$ increased linearly but accelerated for the other cultures (Fig. 6I). After 29 hours, the fastest growth was observed in culture $B$; cultures $C$ and $D$ were growing slower and at a similar rate. Culture $E$ was growing considerably slower than cultures B-D, and finally, culture E was growing very slowly (Table 3).

Figure 6. Three types of measurements describe the growth of P. chrysosporium on different substrates. Graph (I) shows the colony growth measured by radial expansion. Graph (II) shows the colony growth by surface coverage of the membrane by the mycelium. Histograms (III) show the coalescence patterns of objects; each spore is counted as an individual particle at time zero. Graph (IV) shows the number of objects versus the total area occupied by P. chrysosporium.

\section{Growth rates as measured by surface colonization}

Image analysis allowed for the determination of the total surface occupied by the spores and mycelia at any given time. This total area consisted of the sum of all the white pixels present on the image. The inferred growth is related specifically to the superficial growth area in the marked surface.

Growth measured in terms of the occupied area was exponential during two distinct periods; $23-29 \mathrm{~h}$ and 29-52 h (Fig. 6 II) (Table 3). Between $23 \mathrm{~h}$ and $29 \mathrm{~h}$, the exponential growth rate of $P$. chrysosporium in 
culture $C$ was the highest $\left(0.326 \mathrm{~h}^{-1}\right)$, followed, in order, by cultures $B, D, E$, and the agar control (culture A) (Table 3). The growth rates of cultures $\mathrm{D}$ and $\mathrm{E}$ were very similar.

During the second period (29-52 h), the ranking from high to low culture growth rates was $B, E, C, D$, and $A$ (Fig. 6 II). The growth rates of cultures $B$ and $E$ were very similar, and $C$ and $D$ were also similar. Culture $E$ showed a rapid increase in growth during this phase compared to all other cultures (Table 3).

Table 3

Occupation rate $(\mu)$ on different substrates. The values of the mean extension rate $(v)$ of the $P$. chrysosporium colony are correlated with the growth measured by surface area occupation for the same time intervals. The coefficient of determination $\left(R^{2}\right)$ was calculated for each regression line.

\begin{tabular}{|c|c|c|c|c|c|c|}
\hline \multirow{4}{*}{$\begin{array}{l}\text { Growth rate } \\
\text { Culture }\end{array}$} & \multicolumn{4}{|l|}{ Occupied area } & \multirow{2}{*}{\multicolumn{2}{|c|}{$\begin{array}{l}\text { Radial expansion } \\
29 \mathrm{~h} \text { to } 52 \mathrm{~h} \text { ( } 4 \text { points) }\end{array}$}} \\
\hline & \multicolumn{2}{|l|}{$23 \mathrm{~h}$ to $29 \mathrm{~h}$ (3 points) } & \multicolumn{2}{|c|}{$29 \mathrm{~h}$ to $52 \mathrm{~h}$ (4 points) } & & \\
\hline & \multirow{2}{*}{$\mu_{1}\left(h^{-1}\right)$ exponential fit } & \multirow[t]{2}{*}{$\mathrm{R}^{2}$} & \multirow{2}{*}{\multicolumn{2}{|c|}{$\begin{array}{l}\mu_{2}\left(h^{-1}\right) \\
\text { exponential fit }\end{array}$}} & $v(\mu \mathrm{m} / \mathrm{h})$ & $\mathrm{R}^{2}$ \\
\hline & & & & & linear fit & \\
\hline$A$ & 0.195 & 0.999 & 0.101 & 0.999 & 71 & 0.813 \\
\hline B & 0.290 & 0.997 & 0.134 & 0.995 & 633 & 0.999 \\
\hline C & 0.326 & 0.999 & 0.124 & 0.996 & 528 & 0.996 \\
\hline D & 0.257 & 0.997 & 0.121 & 0.998 & 497 & 0.986 \\
\hline E & 0.248 & 0.957 & 0.133 & 0.989 & 347 & 0.970 \\
\hline
\end{tabular}


Table 4

Average size of counted objects during the growth period 0-29 hours.

\section{Occupied area in $\mu \mathrm{m}^{2}$, (no. of objects)}

\begin{tabular}{llllll} 
& Time (h) & $\mathbf{0}$ & 23 & 26 & 29 \\
Culture & A & $5.64 \times 10^{2}(715)$ & $1.76 \times 10^{3}(680)$ & $3.23 \times 10^{3}(645)$ & $6.35 \times 10^{3}(605)$ \\
\hline B & $5.20 \times 10^{2}(687)$ & $4.39 \times 10^{3}(627)$ & $1.24 \times 10^{4}(485)$ & $7.48 \times 10^{4}(209)$ \\
\hline C & $6.64 \times 10^{2}(648)$ & $3.65 \times 10^{3}(588)$ & $1.26 \times 10^{4}(472)$ & $1.27 \times 10^{5}(120)$ \\
\hline D & $5.83 \times 10^{2}(660)$ & $3.10 \times 10^{3}(598)$ & $8.12 \times 10^{3}(533)$ & $2.04 \times 10^{4}(424)$ \\
\hline E & $6.48 \times 10^{2}(645)$ & $1.53 \times 10^{3}(628)$ & $4.42 \times 10^{3}(601)$ & $8.11 \times 10^{3}(524)$
\end{tabular}

Legend: The area is reported in $\mu \mathrm{m}^{2}$; the number of individual objects counted is reported in brackets. After 29 hours, it was no longer possible to count the number of objects due to the high degree of coalescence. At the next time point, $46.5 \mathrm{~h}$, there remained 26 individual objects on culture $A$ and just a single object on each of the other cultures. The number of spores deposited on the membrane at time zero varied between 645 and 715, indicating the reproducibility of the inoculation procedure.

\section{Chemical analysis of solid and soluble fractions of pre-treated miscanthus by FTIR}

FTIR spectroscopy of the multiple miscanthus fractions used for $P$. chrysosporium growth provided rapid semi-quantitative information on the functional groups present, and therefore, on the polymers and molecules potentially available for fungal growth within the substrates. All the substrates in cultures B to E were analyzed (Table 1). The correspondence between the name of the FTIR sample and the type of the substrate from which it is originated is in Table 1 and Fig. 1.

Table 5

Selected absorption band data which correspond to the wavelength of the spectra for the solid and soluble fractions.

\begin{tabular}{|c|c|c|c|c|c|c|c|c|c|c|c|}
\hline \multicolumn{2}{|c|}{ Functional groups } & $\mathrm{HC}$ & L & L & L & L-C & $\mathrm{C}-\mathrm{HC}$ & C & $\mathrm{C}-\mathrm{HC}$ & & $\mathbf{L}$ \\
\hline \multicolumn{2}{|c|}{$\begin{array}{l}\text { Wavenumbers }\left(\mathrm{cm}^{-}\right. \\
\text {1) }\end{array}$} & 1734 & 1605 & 1514 & 1463 & 1427 & 1376 & 1322 & 1055 & 1036 & 896 \\
\hline \multirow[t]{5}{*}{$\begin{array}{l}\text { Samples \& } \\
\text { absorbances }\end{array}$} & $\begin{array}{l}\text { FTIR- } \\
\mathrm{C}^{\mathrm{C} 1}\end{array}$ & 0.2 & 0.6 & 0.2 & 0.2 & 0.2 & 0.2 & 0.8 & 0.8 & 0.7 & 0.0 \\
\hline & $\begin{array}{l}\text { FTIR- } \\
\mathrm{EW} \\
\mathrm{C2}\end{array}$ & 0.2 & 0.6 & 0.2 & 0.2 & 0.2 & 0.2 & 0.7 & 0.7 & 0.8 & 0.0 \\
\hline & $\begin{array}{l}\text { FTIR- } \\
\text { B }\end{array}$ & 0.5 & 0.5 & 0.3 & 0.3 & 0.3 & 0.3 & 1.3 & 1.3 & 1.2 & 0.1 \\
\hline & $\begin{array}{l}\text { FTIR- } \\
\text { D }\end{array}$ & 0.6 & 0.5 & 0.3 & 0.3 & 0.3 & 0.3 & 1.2 & 1.2 & 1.2 & 0.2 \\
\hline & $\begin{array}{l}\text { FTIR- } \\
\text { E }\end{array}$ & 0.5 & 0.5 & 0.3 & 0.3 & 0.3 & 0.3 & 1.2 & 1.2 & 1.2 & 0.1 \\
\hline
\end{tabular}




\section{Legend}

Cellulose (C), hemicellulose (HC), and lignin (L). ${ }^{\mathrm{C} 1}$ represents $1.5 \%$ and ${ }^{\mathrm{C} 2} 0.25 \%$ of the total substrate in culture $\mathrm{B}$. The main differences between the fractions are highlighted in black or grey.

The main functional groups were assigned to cellulose (C), hemicellulose $(\mathrm{HC})$ and lignin $(\mathrm{L})$ in FTIR spectra according to the literature: a (Stewart and Morrison 1992), b(Sun et al. 2000), '(Geng et al. 2003), ${ }^{d}$ (Schwanninger et al. 2004), ${ }^{e}$ (Sun et al. 2005), ${ }^{f}\left(X u\right.$ et al. 2006a), ${ }^{g}$ (Xu et al. 2006b), ${ }^{h}$ (Belmokhtar 2012), ${ }^{i}(X u$ et al. 2013), ${ }^{k}$ (Ferrer et al. 2016), '(Lara-Serrano et al. 2018), ${ }^{m}$ (Li et al. 2018), and ${ }^{n}$ (Lavarda et al. 2019).

The FTIR spectra of substrates used in cultures B, D, and E are almost identical, suggesting few changes in the relative content of lignin, hemicellulose, and cellulose due to the pre-treatment. All these substrates contained solid fractions. Results for samples $C$ and $E w$ were similar but different from samples $B, D$, and $E$, especially for the functional groups related to xylan $\left(1734 \mathrm{~cm}^{-1}\right)$ and aromatic compounds $\left(1605 \mathrm{~cm}^{-1}\right)$. The soluble material remaining in substrate $D$ was similar to substrate $C$ (Table 5 ), demonstrating that the liquid fraction is also present in the unwashed solids fraction.

The elemental (CHNSO) analysis of miscanthus, agar, and the nitrocellulose membrane showed the total absence of nitrogen and sulfur in miscanthus, while the two elements existed in the nitrocellulose membrane (Table 6).

Table 6

Elemental analysis of untreated miscanthus, agar, and the nitrocellulose membrane.

\begin{tabular}{|llllll|}
\hline $\begin{array}{l}\text { CHNOS composition } \\
\text { Element of device }\end{array}$ & $\% \mathrm{C}$ & $\% \mathrm{H}$ & $\% \mathrm{~N}$ & $\% \mathrm{~S}$ & $\% \mathrm{O}$ \\
\hline Miscanthus $x$ giganteus & $45.9 \pm 1.6$ & $6.0 \pm 0.2$ & 0.0 & 0.0 & $48.1 \pm 1.8$ \\
\hline Nitrocellulose membrane & $26.3 \pm 1.9$ & $2.6 \pm 0.5$ & $11.0 \pm 1.0$ & $0.6 \pm 0.1$ & $59.4 \pm 3.6$ \\
\hline Agar & $42.7 \pm 0.2$ & $6.4 \pm 0.1$ & 0.0 & $0.9 \pm 0.0$ & $50.0 \pm 0.3$ \\
\hline
\end{tabular}

\section{Legend}

The average percentage by mass of each element of total CHNSO is represented for duplicates of samples at $0 \%$ moisture.

\section{Discussion}

The main challenge in estimating the growth and morphological development of $P$. chrysosporium by nondestructive microscopic observations was to develop a method for estimating the fungal biomass on natural lignocellulosic biomass and its fractions. Autoclaving miscanthus in aqueous suspension gave two fractions (soluble and solid) through physical separation (Fig. 1). Growth of $P$. chrysosporium on each fraction of the biomass was measured using four different methods: 1) the spore germination rate, 2) the coalescence rate, 3) the radial expansion of the mycelial colony, and 4) the surface occupation wherein the actual surface 
covered by the mycelium was calculated. Of these methods, surface occupation proved to be the best method because it provided information about $P$. chrysosporium growth continually throughout the incubation period. The rate of surface occupation was used to measure fungal growth on each substrate fraction. Other researchers have reported the radial growth of brown rot fungi Postia placenta at a constant rate on the agar surface and concomitant fungal growth into the agar (Carlile 1995; Du et al. 2016). The latter was directly related to the average growth rate of the tips (Du et al. 2019).

The substrates studied were the non-fractionated (B), the soluble (C), the unwashed solid (D), and washed solid (E) fractions. Substrate (B) differed from the other fractions in that it was sterilized in the agar medium, whereas, the other fractions were sterilized in aqueous suspensions and mixed with the agar solution post sterilization. The application of an inverted grey nitrocellulose membrane to support spore deposition, germination, and mycelial growth was the particular innovation that allowed good image acquisition in a non-destructive manner. The porous membrane allowed diffusion of water and nutrients to the spores and the developing mycelium while acting as a physical barrier that prevented observable mixing of the organism and its substrate. Any possible enzymes would have diffused in the opposite direction to contact the substrate. The success of this experimental protocol was evident from the high spore viability observed.

The experimental system provided good contrast for the visualization of the mycelia, facilitating image acquisition and analysis. Spore adhesion to the surface was strong enough to maintain their original positions throughout growth (Figs. 3 \& 4).

Agar was the common ingredient in all cultures, principally to supply moisture throughout mycelial development while keeping the membrane flat. The agar also acted as the carrier for the substrate, although weak fungal growth on agar (A) without any additional substrate was observed (Fig. 3). Agar-degrading bacteria have been previously reported in the literature (Chi et al. 2012), capable of growing on agar while utilizing it as the sole nutrient source. Separate experiments (data not shown) showed weak growth on agar alone without the nitrocellulose membrane. The decomposition of agar ingredients (water-soluble polysaccharide) during sterilization could provide carbon and nitrogen sources for spore germination (Hadar and Tirosh 1997; Sephton-Clark and Voelz 2018), enabling this low level of growth.

The area colonized by the mycelia after 52 hours depended on the substrate present in the agar under the membrane (Fig. 5). The average areas covered by P. chrysosporium containing any of the substrates tested ( $B$ to $E$ fractions) were, without exception, larger than the agar control (culture $A$ ). The fastest overall growth rate was obtained on the non-fractionated substrate $B$ (culture $B$ ). Although the early growth rate was faster with the soluble fraction alone (culture $\mathrm{C}$ ), growth on the non-fractionated substrate accelerated and by 52 hours had surpassed the extent of growth on the soluble fraction (culture C). Neurospora crassa, Arthrobotrys. oligospora and Trichoderma reesei showed different growth behaviors on PDA and LMN medium. Neurospora crassa colonized the entire PDA medium zone $\left(\mu \mathrm{m}^{2}\right)$ in less time $(<24$ hours) than on LMN (40 hours). It generated more hyphal tips, and its mycelial network was denser on PDA. All strains showed the same performance on LMN, but not on PDA (Vidal-Diez de Ulzurrun et al. 2019).

Generally, growth on the unfractionated substrate $B$ and the soluble extract $C$ were similar. Growth on the washed and unwashed substrates ( $C$ and $D$ ) was also similar, but the growth profiles of the two cultures were 
different. Growth on the unwashed substrate (C) was initially relatively fast compared to that on washed solids (D). Initially, the growth in culture D resembled that of the agar control culture (E). On the other hand, once growth on the miscanthus solid fractions began, it proceeded rapidly (Fig. 6 II). This observation suggests that the soluble fraction is initially more available to the fungus but that once the solid fraction becomes available due to enzyme production, the rate of its assimilation is similar to that of the soluble fraction. The growth on the solid fraction can be quite slow initially but then accelerates once growth is established. This pattern is most evident from the growth speed measured on the washed solids (culture E). When available, the soluble and the solid components of the substrate are consumed at the same time, but the easily assimilable component of the soluble fraction can prompt a fast-initial growth rate. Similarly, the simultaneous consumption of both soluble and insoluble components on wheat straw by Ganoderma Iucidium has been reported (Gupta and Jana 2018).

After 52 hours, the growth rate observed on complete substrate could be reproduced arithmetically by the sum of the growth rates on cultures $C$ and D (Table 7). The additivity started after 46.5 hours (Fig. 6II).

Table 7

The additive effect of different substrate fractions on $P$. chrysosporium growth at $52 \mathrm{~h}$.

\begin{tabular}{|lllllll|}
\hline Calculation & B-A & C-A & D-A & E-A & (C-A)+(D-A) & (C-A)+(E-A) \\
\hline $\begin{array}{l}\text { Occupied area } \\
\left(\mu \mathrm{m}^{2} \times \mathbf{1 0}^{-\mathbf{8}}\right)\end{array}$ & 2.6 & 1.8 & 1.0 & 0.4 & 2.8 & 2.3 \\
\hline $\begin{array}{l}\text { Legend: B-A C-A, D-A, E-A: correspond to the mean occupied area on the defined substrate (B,C,D,E) minus } \\
\text { the mean occupied area on the substrate (A). (C-A)+(D-A): The addition of the mean occupied area on the } \\
\text { soluble fraction (Substrate C) and that on the unwashed solid (Substrate D) after the subtraction of the } \\
\text { mean occupied area on agar (Substrate A) from each culture. }\end{array}$ & \\
\hline
\end{tabular}

Microbial growth is conventionally characterized by the exponential rate of growth $(\mu)$ and is indicated as per unit time. This growth is a species- and condition-dependent constant value and can be used in conjunction with Monod's equation to model microbial growth (Olorunnisola et al. 2018). The determination of mycelial growth and fungal biomass formation is rather challenging due to the close association of the fungal biomass with the substrate. As the former increases, the latter decreases, rendering biomass determination difficult.

The mycelium tends to fill the initial area where the spores are deposited; therefore, early growth is not captured by radial colony expansion. After $29 \mathrm{~h}$ of incubation, the growth of $P$. chrysosporium could be satisfactorily followed either by surface occupation or radial growth rates (Fig. 6 \& Table 3). We have demonstrated that colony surface colonization, as determined by microscopy and image analysis, is a suitable method for following mycelial growth non-destructively but was limited by the growth of the mycelium in 3D. The determination of the very early growth rate is of particular interest as growth can be considered free of any restrictions at this early stage. Coalescence in time proved useful for measuring the initial growth rate, but image analysis in this method was very labor-intensive and was limited by the coalescence of objects within the initial droplet area. 
The observations in this work are consistent with the hypothesis that $P$. chrysosporium initially consumes the soluble fraction of miscanthus while it produces the metabolic machinery required to degrade the solid fraction. Once hydrolytic and oxidative enzymes are secreted, the solid fraction could be digested, and the mycelium occupied the surface at an even faster rate by efficient co-utilization of the two fractions. The coutilization of soluble and insoluble nutrients of wheat straw has been reported to result in the highest fungal growth and laccase production by G. Iucidium (Gupta and Jana 2018).

In our study, growth was measured in 2D; therefore, the penetration of the mycelium through the membrane and into the agar could not be observed. It has been shown that hyphae, in direct contact with a PET membrane, penetrate membrane pores $(3 \mu \mathrm{m})$, grow through the membrane, and emerge on the other side (Morris and Bone 1998).

In our experiments, $P$. chrysosporium was not able to grow on moist nitrocellulose membrane even after 52 hours (data not shown) in the absence of agar. The absence of readily available sources of carbon does not allow the invasion of the nitrocellulose support by the organism. We propose that the soluble nutrients can impregnate the support and thus feed the spores on the side that is exposed to the air.

The FTIR data analysis showed that the soluble molecules (sample FTIR-Ew) associated with the solid fractions of the substrate had the same composition as the soluble fraction (Sample FTIR-C) (Table 5). Both contained lignin and carbohydrates, which means that substrate D contained two sub-fractions: the easily assimilated soluble fraction and the physically associated solid fraction. The latter was initially more difficult to digest.

The FTIR data are consistent with what is generally observed after autoclaving lignocellulosic material. In mild hot water pre-treatment, it can be supposed that limited hydrolysis and rearrangement of hemicelluloses and lignin occurred (Assor et al. 2009), leading to the release of small amounts of acid-soluble lignin, oligosaccharides, monomer sugars (xylose, glucose) and other extractives (phenolic acids, aliphatic esters, etc.) into the liquid phase (Kristensen et al. 2008; Yang et al. 2016). The soluble components were demonstrated to be good substrates for boosting the initial growth of the $P$. chrysosporium under our experimental conditions.

Elemental analysis of $\mathrm{C}, \mathrm{H}, \mathrm{N}, \mathrm{S}$, and $\mathrm{O}$ (Table 6 ) showed a total absence of nitrogen ( $0 \%$ ) in miscanthus and agar, but it was present at $11 \%(\mathrm{w} / \mathrm{w})$ in the nitrocellulose membrane. Sulfur was not detected in miscanthus but was in the agar and nitrocellulose membrane at 0.9 and $0.5 \%$, respectively. The liquid fraction of miscanthus obtained by a mechanical press contained $0.8 \% \mathrm{~N}$ and $1 \% \mathrm{~S}$ as well as other minerals (Xiu et al. 2017). Agar is composed of carbon, hydrogen, oxygen, and sulfur (Bornman and Barnard 1993). Although the growth of the organisms on nitrocellulose alone is very slow (Saratovskikh et al. 2018) and non-existent on the time scale of the experiment (data not shown), we propose that $P$. chrysosporium grows using the carbon and nitrogen sources either present in the treated miscanthus or small degradation products of the agar. Nitrogen content was suggested to play a crucial role in mediating the growth of $P$. chrysosporium. and the production of lignocellulolytic enzymes. A high $\mathrm{C} / \mathrm{N}$ ratio is generally assumed to offer the best growth and activities of LiP and MnP (Gao and Wen 2005; Huang et al. 2020). Under nitrogen-poor conditions, it is supposed that $P$. chrysosporium recycles nitrogen in its cells (Ulmer et al. 1983). Under these circumstances, 
the elemental nitrogen from the nitrocellulose membrane could be utilized with the carbon from the miscanthus.

\section{Conclusions}

An efficient method based on microscopy and image analysis was developed to follow and quantify $P$. chrysosporium growth on miscanthus fractions, and our results showed growth differences of the microorganism on the different fractions. The growth was affected from the very beginning by the nature of the substrate.

Phanerochaete chrysosporium was able to grow weakly on agar alone as a substrate, and after correcting the results for this growth, the surface occupation was used as a measure of growth. The coalescence dynamic as measurement could offer a new rapid method for early growth analysis. The methods used in this study were limited to 2D observation on physical support, which prevented the detailed analysis of the real fungal biomass such as the volume of mycelium in voxels and its behavior in direct contact with the natural solid lignocellulosic biomass.

Different phases of growth could be identified. From 0 to $23 \mathrm{~h}$, the spores germinated and occupied the area of the droplet initially placed on the membrane. During this phase, growth was fastest on the soluble fraction of miscanthus. The presence of washed solids did not influence the growth rate of the organisms compared with agar alone, so the solid fraction was not immediately attacked. A second growth phase between 23 and $29 \mathrm{~h}$ showed a rapid acceleration of all growth rates. Finally, during the last growth phase, the cultures containing solid fractions overtook the growth of culture $C$ that contained only the soluble fraction. This leads us to conclude that degradation of the solid fraction by P. chrysosporium does not pose a problem to the organism, and once the enzymic machinery is in place, the organism can grow even more rapidly on the solid fraction.

This method for measurement of fungal growth may be applied to other studies to help further our understanding of the mechanism in which the fungi attack their substrate. The study reported here should be followed by a particular focus on the temporal production of the enzymes, such as cellulases ( $\beta$ glucosidases, endoglucanases, cellobiohydrolases), hemicellulases (endo-1,4- $\beta$-xylanase, xylan 1,4- $\beta$ xylosidase), and ligninases (manganese peroxidase, lignin peroxidase).

\section{Declarations}

\section{ACKNOWLEDGMENTS}

The authors are thankful to Hasna Nait m'Barek and Barbara Malinowaska for the elemental analysis. We thank Véronique Gaillet for providing training in fungal culture techniques. Anouck Habrant and Brigitte Chabbert assisted with the FTIR analysis, and Gonzague Alavoine helped with the milling procedure.

The Chair of Biotechnology of CentraleSupélec is grateful to the Grand Reims, the Marne department, and the Grand Est region for their financial support. 


\section{DECLARATIONS}

The microbiological work presented in this study did not encompass any ethical considerations. All authors, freely give their consent for publication in IMA Fungus. The manuscript has not been submitted to any other journal. The materials and methods section is sufficiently detailed for the experiments to be repeated. Access to raw experimental data is available to the journal should the reviewers request it. The experiments were conceived by all the authors, the experimental work was solely performed by Hassan Khalil, all authors participated in data analysis and interpretation. The manuscript was prepared by the participation of all authors. There are no competing interests between the authors.

\section{References}

\section{10.1016/j.jprot.}

Adav Sunil S, Ravindran A, Siu Kwan S (2012) « Quantitative Proteomic Analysis of Lignocellulolytic Enzymes by Phanerochaete Chrysosporium on Different Lignocellulosic Biomass ». Journal of Proteomics 75 (5): 1493-1504. https://doi.org/10.1016/j.jprot.2011.11.020.Anderson Eric, Rebecca Arundale, Matthew Maughan, Adebosola Oladeinde, Andrew Wycislo, and Thomas Voigt. 2011. "Growth and Agronomy of Miscanthus x Giganteus for Biomass Production ». Biofuels 2 (1): 71-87. https://doi.org/10.4155/bfs.10.80

2. Andrade Meire Cristina Nogueira de 10.1590/S1517-838220080003000034

Andrade Meire Cristina Nogueira de, Zied DC, Marli Teixeira de Almeida Minhoni, and João Kopytowski Filho (2008) " Yield of four Agaricus bisporus strains in three compost formulations and chemical composition analyses of the mushrooms ». Brazilian Journal of Microbiology 39 (3): 593-98. https://doi.org/10.1590/S1517-838220080003000034

3. Assor Carole V, Placet B, Chabbert A, Habrant C, Lapierre B, Pollet, Patrick Perré (2009) « Concomitant Changes in Viscoelastic Properties and Amorphous Polymers during the Hydrothermal Treatment of Hardwood and Softwood ». J Agric Food Chem 57 (15): 6830-6837. https://doi.org/10.1021/jf901373s

4. Auer N, Veness RG, et Evans CS (1999) « Bioremediation of nitrocellulose pollution » 7 (janvier): 301-4

5. Bajpai Pratima 10.1007/978-981-10-0687-6_2

Bajpai Pratima (2016) «Structure of Lignocellulosic Biomass ». In Pretreatment of Lignocellulosic Biomass for Biofuel Production, par Bajpai P, 7-12. Singapore: Springer Singapore. https://doi.org/10.1007/978-981-10-0687-6_2

6. Chan BDavidJCecilia, Williams GA (2007) « Nitrocellulose as a General Tool for Fungal Slide Mounts». J Clin Microbiol 45(3):1074-1075. https://doi.org/10.1128/JCM.01609-06

7. Barry David J, Gwilym A, Williams, Chan C (2015) « Automated Analysis of Filamentous Microbial Morphology with AnaMorf ». Biotechnol Prog 31(3):849-852. https://doi.org/10.1002/btpr.2087

8. Belmokhtar Nassim (2012) «Etude de la saccharification enzymatique du miscanthus par les cocktails cellulolytiques de Trichoderma reesei ». Thesis, Reims. http://www.theses.fr/2012REIMS028 
9. Bornman JJ, Barnard RO (1993) « The Possible Use of Agar Gel in Plant Nutritional Studies ». South African Journal of Plant Soil 10(3):146-149. https://doi.org/10.1080/02571862.1993.10634661

10. Broda Paul

10.1007/978-94-011-1672-5_8

Broda Paul (1993) «Biotechnology in the Degradation and Utilization of Lignocellulose ». In Microorganisms to Combat Pollution, édité par Rosenberg E, 95-114. Dordrecht: Springer Netherlands. https://doi.org/10.1007/978-94-011-1672-5_8

11. Carlile MJ (1995) «The Success of the Hypha and Mycelium ». In: The Growing Fungus, édité par Neil A. R. Gow et Geoffrey M. Gadd, 3-19. Springer Netherlands, Dordrecht. https://doi.org/10.1007/978-0-58527576-5_1

12. Chazal Richard P, Robert S, Durand M-F, Devaux L, Saulnier C, Lapierre, Fabienne Guillon (2014) « Investigating Lignin Key Features in Maize Lignocelluloses Using Infrared Spectroscopy ». Appl Spectrosc 68 (12): 1342-1347. https://doi.org/10.1366/14-07472

13. 10.1007/978-94-007-6043-1_2

Chen H (2013) « Biotechnology Principles of Solid State Fermentation ». In Modern Solid State Fermentation, par Hongzhang Chen, 23-74. Dordrecht: Springer Netherlands.

https://doi.org/10.1007/978-94-007-6043-1_2

14. Chi Won-Jae, Yong-Keun Chang, and Soon-Kwang H (2012) « Agar Degradation by Microorganisms and Agar-Degrading Enzymes ». Appl Microbiol Biotechnol 94(4):917-930. https://doi.org/10.1007/s00253012-4023-2

15. Cook PE, Owens JD, Campbell-Platt G (1991) «Fungal Growth during Rice Tapé Fermentation ». Lett Appl Microbiol 13(3):123-125. https://doi.org/10.1111/j.1472-765X.1991.tb00587.x

16. Couri S, Merces $P$ (2006) « Digital image processing as a tool to monitor biomass growth in Aspergillus niger 3T5B8 solid-state fermentation: preliminary results ». J Microsc 224(3):290-297

17. Czymmek Kirk, and Joanne Whallon (1994) « Confocal Microscopy in Mycological Research ». Exp Mycol 18:275-293

18. Melissa Limoeiro Estrada Gutarra

10.1016/j.micron.2017.04.001

De AF Pereira, Denise Maria Guimarães Freire, Ulysses Lins, and Melissa Limoeiro Estrada Gutarra. 2017. «Surface Imaging of the Filamentous Fungus Penicillium Simplicissimum Growing in a Solid-State Fermentation System ». Micron 99 (août): 19-25. https://doi.org/10.1016/j.micron.2017.04.001

19. Jan Van den Bulcke, Joris Van Acker, and Bernard De Baets https://doi.org/10.1186/s43008-019-0009-3

De LLiselotte,GVidal-Diez de Ulzurrun, Baetens JM, Jan Van den Bulcke, Joris Van Acker, and Bernard De Baets. 2019. "Analysis of Spatio-Temporal Fungal Growth Dynamics under Different Environmental Conditions ». IMA Fungus 10 (1): 7. https://doi.org/10.1186/s43008-019-0009-3

20. Du Huan P, Lv M, Ayouz A, Besserer, Patrick, Perré (2016) « Morphological Characterization and Quantification of the Mycelial Growth of the Brown-Rot Fungus Postia Placenta for Modeling Purposes ». Édité par Daniel Cullen. PLOS ONE 11(9):e0162469. https://doi.org/10.1371/journal.pone.0162469 
21. Du Huan Thi-Bich-Thuy, Tran, Perré P (2019) «A 3-Variable PDE Model for Predicting Fungal Growth Derived from Microscopic Mechanisms ». J Theor Biol 470 (juin):90-100.

https://doi.org/10.1016/j.jtbi.2019.03.015

22. Dubis Bogdan K, Bułkowska, Małgorzata Lewandowska, Władysław Szempliński, Krzysztof Józef Jankowski, Jakub Idźkowski, Natalia Kordala, and Karolina Szymańska. 2017. « Effect of Different Nitrogen Fertilizer Treatments on the Conversion of Miscanthus x giganteus to Ethanol ». Bioresource Technology 243 (novembre): 731-37. https://doi.org/10.1016/j.biortech.2017.07.005

23. Dutra Júlio CV, Selma daC, Terzi JV, Bevilaqua, Mônica CT, Damaso S, Couri MAP, Langone, Senna LF (2008) « Lipase Production in Solid-State Fermentation Monitoring Biomass Growth of Aspergillus Niger Using Digital Image Processing ». Appl Biochem Biotechnol 147(1-3):63-75. https://doi.org/10.1007/s12010-007-8068-0

24. 10.1007/978-3-642-46687-8_1

Eriksson Karl-ErikL, Robert A, Blanchette, and Paul Ander (1990) « Morphological Aspects of Wood Degradation by Fungi and Bacteria ». In Microbial and Enzymatic Degradation of Wood and Wood Components, édité par Karl-Erik L. Eriksson, Robert A. Blanchette, et Paul Ander, 1-87. Springer Series in Wood Science. Berlin, Heidelberg: Springer. https://doi.org/10.1007/978-3-642-46687-8_1

25. 10.1007/978-3-319-41414-0_3

Ferrer A, Alciaturi C, Faneite A, Josybel, Ríos (2016) « Analyses of Biomass Fibers by XRD, FT-IR, and NIR ». In Analytical Techniques and Methods for Biomass, édité par Sílvio Vaz, 45-83. Cham: Springer International Publishing. https://doi.org/10.1007/978-3-319-41414-0_3

26. France Miscanthus (2020) « Les chiffres de la filière française ». France Miscanthus. 2020. https://www.france-miscanthus.org/le-miscanthus-en-chiffres/. Accessed on 2020-06-16 14:07:51

27. Gao Da-wen, Xiang-hua Wen (2005) «Effect on nitrogen concentration in culture mediums on growth and enzyme production of Phanerochaete chrysosporium ». J Environ Sci 17(2):190-193

28. Geng ZC, Sun RC, Sun XF, Lu Q (2003) « Comparative Study of Hemicelluloses Released during TwoStage Treatments with Acidic Organosolv and Alkaline Peroxide from Caligonum Monogoliacum and Tamarix Spp ». Polym Degrad Stab 80(2):315-325. https://doi.org/10.1016/S0141-3910(03)00015-6

29. Gladchenko MA, Gaidamaka SN, Murygina VP, Lifshits AB, Cherenkov PG (2015) « Laboratory Simulation Study of the Solid-Phase Aerobic Fermentation of Nitrocellulose-Containing Wastewater Sludge ». Russian Journal of Physical Chemistry B 9(3):429-435. https://doi.org/10.1134/S1990793115030161

30. Gougouli Maria, Koutsoumanis KP (2013) « Relation between Germination and Mycelium Growth of Individual Fungal Spores ». Int J Food Microbiol 161(3):231-239.

https://doi.org/10.1016/j.ijfoodmicro.2012.12.006

31. Gowthaman MK, Chundakkadu, Krishna, Moo-Young M (2001) «Fungal Solid State Fermentation - an Overview ». Applied Mycology Biotechnology, 1:305-352. Elsevier. https://doi.org/10.1016/S18745334(01)80014-9

32. Graminha EBN, Gonçalves AZL, Pirota RDPB, Balsalobre MAA, Da Silva R, Gomes E (2008) « Enzyme Production by Solid-State Fermentation: Application to Animal Nutrition ». Anim Feed Sci Technol 144(1-2):1-22. https://doi.org/10.1016/j.anifeedsci.2007.09.029

Page $21 / 31$ 
33. $10.1007 /$ s13205-017-1054-5

Gupta, Antriksh, Asim Kumar J (2018) «Effects of Wheat Straw Solid Contents in Fermentation Media on Utilization of Soluble/Insoluble Nutrient, Fungal Growth and Laccase Production ». 3 Biotech 8 (1): 35. https://doi.org/10.1007/s13205-017-1054-5

34. Hadar Julia, and Tsvi Tirosh (1997) « Autoclave emissions-Hazardous or not ». Journal of the American Biological Safety Association 2(3):44-51

35. Hassouni H, Ismaili-Alaoui M (2007) « Comparative spore germination of filamentous fungi on solid state fermentation under different culture conditions ». Micologia Aplicada International 19(1):7-15

36. Heaton E (2004) «A Quantitative Review Comparing the Yields of Two Candidate C4 Perennial Biomass Crops in Relation to Nitrogen, Temperature and Water ». Biomass Bioenerg 27(1):21-30. https://doi.org/10.1016/j.biombioe.2003.10.005

37. Huang Saihua D, Huang Q, Wu M, Hou X, Tang, and Jian Zhou (2020) « Effect of Environmental C/N Ratio on Activities of Lignin-Degrading Enzymes Produced by Phanerochaete Chrysosporium ». Pedosphere 30(2):285-292. https://doi.org/10.1016/S1002-0160(17)60391-6

38. Janse Bernard JH, Gaskell J, Akhtar M, et Daniel Cullen (1998) « Expression of Phanerochaete chrysosporium Genes Encoding Lignin Peroxidases, Manganese Peroxidases, and Glyoxal Oxidase in Wood ». Appl Environ Microbiol 64 (9): 3536-3538

39. Jha Krishna SK, Khare, Gandhi AP (1995) «Solid-State Fermentation of Soyhull for the Production of Cellulase ». Biores Technol 54(3):321-322. https://doi.org/10.1016/0960-8524(95)00154-9

40. Judet Daniela M, Bensoussan J-M Perrier-Cornet, and Philippe Dantigny (2008) « Distributions of the Growth Rate of the Germ Tubes and Germination Time of Penicillium Chrysogenum Conidia Depend on Water Activity ». Food Microbiol 25(7):902-907. https://doi.org/10.1016/j.fm.2008.05.007

41. Kameshwar Ayyappa Kumar Sista, and Qin W (2017) « Metadata Analysis of Phanerochaete Chrysosporium Gene Expression Data Identified Common CAZymes Encoding Gene Expression Profiles Involved in Cellulose and Hemicellulose Degradation ». International Journal of Biological Sciences 13 (1): 85-99. https://doi.org/10.7150/ijbs.17390

42. Kersten, Phil, and Dan Cullen (2007) «Extracellular Oxidative Systems of the Lignin-Degrading Basidiomycete Phanerochaete Chrysosporium ». Fungal Genet Biol 44(2):77-87. https://doi.org/10.1016/j.fgb.2006.07.007

43. Khullar Esha BS, Dien KD, Rausch ME, Tumbleson, and Vijay Singh (2013) « Effect of Particle Size on Enzymatic Hydrolysis of Pretreated Miscanthus ». Ind Crops Prod 44(janvier):11-17. https://doi.org/10.1016/j.indcrop.2012.10.015

44. Konwar Lakhya J, Mikkola J-P, Bordoloi N, Saikia R, Chutia RS, Kataki R (2018) « Chap. 3 - Sidestreams From Bioenergy and Biorefinery Complexes as a Resource for Circular Bioeconomy ». In Waste Biorefinery, édité par Thallada Bhaskar, Ashok Pandey, S. Venkata Mohan, Duu-Jong Lee, et Samir Kumar Khanal, 85-125. Elsevier. https://doi.org/10.1016/B978-0-444-63992-9.00003-3

45. $10.13031 / 2013.6224$

Krishna C, Sue Nokes (2001) « Influence of inoculum size on phytase production and growth in solidstate fermentation by Aspergillus niger ». Transactions of the ASAE 44 (janvier). 
https://doi.org/10.13031/2013.6224

46. Kristensen Jan B, Lisbeth G, Thygesen C, Felby H, Jørgensen, and Thomas Elder (2008) « Cell-wall structural changes in wheat straw pretreated for bioethanol production ». Biotechnol Biofuels 1(1):5. https://doi.org/10.1186/1754-6834-1-5

47. Kumar D, Jain VK, Shanker G, Srivastava A (2003) « Citric Acid Production by Solid State Fermentation Using Sugarcane Bagasse ». Process Biochem 38(12):1731-1738. https://doi.org/10.1016/S00329592(02)00252-2

48. 10.1021/acssuschemeng.8b00953

Lara-Serrano Marta, Felicia Sáez Angulo, María José Negro, Silvia Morales-delaRosa, Jose M, CamposMartin, Jose LG, Fierro (2018) « Second-Generation Bioethanol Production Combining Simultaneous Fermentation and Saccharification of IL-Pretreated Barley Straw ». ACS Sustainable Chemistry \& Engineering 6 (5): 7086-95. https://doi.org/10.1021/acssuschemeng.8b00953

49. Lavarda Giulia S, Morales-delaRosa P, Centomo JM, Campos-Martin M, Zecca, Fierro JLG (2019) « GelType and Macroporous Cross-Linked Copolymers Functionalized with Acid Groups for the Hydrolysis of Wheat Straw Pretreated with an Ionic Liquid ». Catalysts 9(8):675. https://doi.org/10.3390/catal9080675

50. Lee W-C, Wei-Chih Kuan (2015) « Miscanthus as Cellulosic Biomass for Bioethanol Production ». Biotechnol J 10(6):840-854. https://doi.org/10.1002/biot.201400704

51. Li Xiaoli Y, Wei J, Xu N, Xu, He Y (2018) «Quantitative Visualization of Lignocellulose Components in Transverse Sections of Moso Bamboo Based on FTIR Macro- and Micro-Spectroscopy Coupled with Chemometrics ». Biotechnol Biofuels 11(1):263. https://doi.org/10.1186/s13068-018-1251-4

52. 10.1016/j.bcab.2019.101467

Londoño-Hernandez Liliana HA, Ruiz T, Cristina Ramírez JA, Ascacio, Raúl Rodríguez-Herrera, and Cristóbal N. Aguilar. 2020. «Fungal Detoxification of Coffee Pulp by Solid-State Fermentation ». Biocatalysis and Agricultural Biotechnology 23 (janvier): 101467.

https://doi.org/10.1016/j.bcab.2019.101467

53. Lonsane BK, Saucedo-Castaneda G, Raimbault M, Roussos S, Viniegra-Gonzalez G, Ghildyal NP, Ramakrishna M, Krishnaiah MM (1992) « Scale-up Strategies for Solid State Fermentation Systems ». Process Biochem 27(5):259-273. https://doi.org/10.1016/0032-9592(92)85011-P

54. Musaalbakri M, Webb C (2017) « Design Aspects of Solid State Fermentation as Applied to Microbial Bioprocessing ». Journal of Applied Biotechnology Bioengineering 4 (1). https://doi.org/10.15406/jabb.2017.04.00094

55. Martinez Diego LF, Larrondo N, Putnam MDS, Gelpke K, Huang J, Chapman, Kevin G, Helfenbein et al (2004) « Genome Sequence of the Lignocellulose Degrading Fungus Phanerochaete Chrysosporium Strain RP78 ». Nat Biotechnol 22(6):695-700. https://doi.org/10.1038/nbt967

56. 10.1007/978-3-662-07426-8_17

Mester T, Varela E, Tien M (2004) « Wood Degradation by Brown-Rot and White-Rot Fungi ». In Genetics and Biotechnology, édité par Ulrich Kück, 355-68. Berlin, Heidelberg: Springer Berlin Heidelberg. https://doi.org/10.1007/978-3-662-07426-8_17 
57. Morris Paul F, and Elizabeth Bone (1998) « Chemotropic and Contract Responses of Phytophthora sojae Hyphae to Soybean Isoflavonoids and Artifical Substrates ». Plant Physiology n 117:1171-1178

58. Nanguy Sidjè Paule-Marina, Perrier-Cornet J-M, Bensoussan M, Dantigny P (2010) « Impact of Water Activity of Diverse Media on Spore Germination of Aspergillus and Penicillium Species ». Int J Food Microbiol 142 (1-2): 273-276. https://doi.org/10.1016/j.ijfoodmicro.2010.06.031

59. Oliveira Luciana A, Santana C, Maranhão R, Miranda V, Lima M, Nascimento, and Lothar Bieber (2010) « Natural resistance of five woods to Phanerochaete chrysosporium degradation ». International Biodeterioration Biodegradation 64(décembre):711-715. https://doi.org/10.1016/j.ibiod.2010.08.001

60. 10.1007/s13205-018-1452-3

Saheed OK, Jamal P, Zahangir Alam Md (2018) « Growth, Substrate Consumption, and Product Formation Kinetics of Phanerochaete Chrysosporium and Schizophyllum Commune Mixed Culture under Solid-State Fermentation of Fruit Peels ». 3 Biotech 8 (10): 429. https://doi.org/10.1007/s13205-0181452-3

61. Pérez J, Muñoz-Dorado J, de la Rubia T, Martínez J (2002) « Biodegradation and Biological Treatments of Cellulose, Hemicellulose and Lignin: An Overview ». Int Microbiol 5(2):53-63. https://doi.org/10.1007/s10123-002-0062-3

62. Preibisch Stephan S, Saalfeld, and Pavel Tomancak (2009) « Globally optimal stitching of tiled 3D microscopic image acquisitions ». Bioinformatics 25(11):1463-1465. https://doi.org/10.1093/bioinformatics/btp184

63. Qin Zhangcai Q, Zhuang X, Zhu X, Cai, Zhang X (2011) « Carbon Consequences and Agricultural Implications of Growing Biofuel Crops on Marginal Agricultural Lands in China ». Environmental Science Technology 45(24):10765-10772. https://doi.org/10.1021/es2024934

64. Raimbault Maurice (1998) «General and microbiological aspects of solid substrate fermentation ». Electron J Biotechnol 1(2):174-188. https://doi.org/10.2225/vol1-issue3-fulltext-9

65. Anamika R, Saykhedkar S, Canaan P, Hartson S, Prade R, Andrew Mort (2012) « Phanerochaete chrysosporium produces a diverse array of extracellular enzymes when grown on sorghum ». Appl Microbiol Biotechnol 93 (janvier): 2075-2089. https://doi.org/10.1007/s00253-012-3907-5

66. Reyes-Moreno C, Romero-Urías C, Milán-Carrillo J, Valdéz-Torres B, Zárate-Márquez E (2000) « Optimization of the solid state fermentation process to obtain tempeh from hardened chickpea (Cicer arietinum L) ». Plant Foods Hum Nutr 55(3):219-228. https://doi.org/10.1023/A:1008192214018

67. Roni MS, Cafferty KG, Hess JR, Jacobson JJ, Kenney KL, Searcy E, Tumuluru JS (2016) « Lignocellulosic Crop Supply Chains (Eg, Miscanthus, Switchgrass, Reed Canary Grass, Rye, Giant Reed, Etc.) ». In Biomass Supply Chains for Bioenergy and Biorefining, 271-91. Elsevier. https://doi.org/10.1016/B978-178242-366-9.00012-5

68. Ropars J, López-Villavicencio M, Snirc A, Lacoste S, Tatiana Giraud (2017) « Blue Cheese-Making Has Shaped the Population Genetic Structure of the Mould Penicillium Roqueforti ». PloS One 12 (3): e0171387. https://doi.org/10.1371/journal.pone.0171387

69. Ruel Katia K, Ambert, Jean-Paul Joseleau (1994) « Influence of the Enzyme Equipment of White-Rot Fungi on the Patterns of Wood Degradation ». FEMS Microbiol Rev 13(2):241-254 
70. Ruiz-Aguilar G, Fernández-Sánchez J, Rodríguez-Vázquez R, Poggi-Varaldo HM, Esparza-García F, Vázquez-Duhalt R (2002) «PCB's Biotransformation by a White-Rot Fungus Under Composting and Liquid Culture Conditions ». Microbiology of Composting, édité par Heribert Insam, Nuntavun Riddech, et Susanne Klammer, pp 287-297. Berlin: Springer. https://doi.org/10.1007/978-3-662-08724-4_24

71. Rytioja Johanna K, Hildén J, Yuzon A, Hatakka, Ronald P, de Vries, Mäkelä MR (2014) « PlantPolysaccharide-Degrading Enzymes from Basidiomycetes ». Microbiology Molecular Biology Reviews: MMBR 78(4):614-649. https://doi.org/10.1128/MMBR.00035-14

72. Abby S, Mos M, Najser J, Daroch M, Joe Gallagher (2018) « Gasification of Miscanthus x Giganteus Pellets in a Fixed Bed Pilot-Scale Unit ». Frontiers in Energy Research 6. https://doi.org/10.3389/fenrg.2018.00091

73. Saratovskikh EA, Shcherbakova VA, Yarullin RN (2018) « Nitrocellulose Degradation by the Fungus Fusarium Solani ». Appl Biochem Microbiol 54(1):45-52. https://doi.org/10.1134/S0003683818010106

74. Sato Shin F, Liu H, Koc, Tien M (2007) « Expression Analysis of Extracellular Proteins from Phanerochaete Chrysosporium Grown on Different Liquid and Solid Substrates ». Microbiology 153(Pt 9):3023-3033. https://doi.org/10.1099/mic.0.2006/000513-0

75. Schwanninger M, Rodrigues JC, Pereira H, Hinterstoisser B (2004) « Effects of Short-Time Vibratory Ball Milling on the Shape of FT-IR Spectra of Wood and Cellulose ». Vib Spectrosc 36(1):23-40. https://doi.org/10.1016/j.vibspec.2004.02.003

76. Sekiguchi J, Gaucher GM (1977) « Conidiogenesis and Secondary Metabolism in Penicillium Urticae ». Appl Environ Microbiol 33(1):147-158

77. Sephton-Clark Poppy CS, Kerstin Voelz (2018) «Spore Germination of Pathogenic Filamentous Fungi ». Adv Appl Microbiol 102:117-157. https://doi.org/10.1016/bs.aambs.2017.10.002

78. Shrestha Prachand, Ana B, Ibáñez S, Bauer SI, Glassman TM, Szaro TD, Bruns, John W, Taylor (2015) « Fungi Isolated from Miscanthus and Sugarcane: Biomass Conversion, Fungal Enzymes, and Hydrolysis of Plant Cell Wall Polymers ». Biotechnol Biofuels 8(1):38. https://doi.org/10.1186/s13068-015-0221-3

79. Soares Marlene P, Christen A, Pandey, Carlos Ricardo Soccol (2000) « Fruity Flavour Production by Ceratocystis Fimbriata Grown on Coffee Husk in Solid-State Fermentation ». Process Biochem 35(8):857-861. https://doi.org/10.1016/S0032-9592(99)00144-2

80. Soccol Carlos Ricardo, Eduardo Scopel Ferreira da Costa, Luiz Alberto Junior Letti, Susan Grace Karp, Adenise Lorenci Woiciechowski, and Luciana Porto de Souza Vandenberghe. 2017. « Recent Developments and Innovations in Solid State Fermentation ». Biotechnology Research and Innovation 1 (1): 52-71. https://doi.org/10.1016/j.biori.2017.01.002

81. Srebotnik Ewald K, Messner, Roland Foisner (1988) «Penetrability of White Rot-Degraded Pine Wood by the Lignin Peroxidase of Phanerochaete Chrysosporium ». Appl Environ Microbiol 54 (11): 2608-2614. https://doi.org/10.1128/AEM.54.11.2608-2614.1988

82. Stewart D, Morrison IM (1992) «FT-IR Spectroscopy as a Tool for the Study of Biological and Chemical Treatments of Barley Straw ». J Sci Food Agric 60(4):431-436. https://doi.org/10.1002/jsfa.2740600405 
83. Sun RunCang J, Tomkinson ShiQing, Wang, Zhu W (2000) « Characterization of Lignins from Wheat Straw by Alkaline Peroxide Treatment ». Polym Degrad Stab 67(1):101-109. https://doi.org/10.1016/S0141-3910(99)00099-3

84. Sun XF, Xu F, Sun RC, Fowler P, Baird MS (2005) « Characteristics of Degraded Cellulose Obtained from Steam-Exploded Wheat Straw ». Carbohyd Res 340(1):97-106.

https://doi.org/10.1016/j.carres.2004.10.022

85. Ulmer D, Leisola M, Puhakka J, Fiechter A (1983) « Phanerochaete Chrysosporium: Growth Pattern and Lignin Degradation ». European Journal of Applied Microbiology Biotechnology 18(3):153-157. https://doi.org/10.1007/BF00498037

86. Urek Razie Ozturk, and Nurdan Kasikara Pazarlioglu (2007) « Enhanced production of manganese peroxidase by Phanerochaete chrysosporium ». Brazilian archives of Biology Technology 50(6):913-920

87. Vanden Wymelenberg A, Gaskell J, Mozuch M, Sabat G, Ralph J, Skyba O, Mansfield SD et al (2010) « Comparative Transcriptome and Secretome Analysis of Wood Decay Fungi Postia Placenta and Phanerochaete Chrysosporium ». Appl Environ Microbiol 76(11):3599-3610. https://doi.org/10.1128/AEM.00058-10

88. Juliana V-C, Ge X, Li andYebo (2016) « Fungal Pretreatment of Non-Sterile Miscanthus for Enhanced Enzymatic Hydrolysis ». Biores Technol 203 (mars):118-123. https://doi.org/10.1016/j.biortech.2015.12.018

89. Vasco-Correa Juliana, et Ajay Shah (2019) « Techno-Economic Bottlenecks of the Fungal Pretreatment of Lignocellulosic Biomass ». Fermentation 5(2):30. https://doi.org/10.3390/fermentation5020030

90. Velmurugan Palanivel H, Hur V, Balachandar S, Kamala-Kannan K-J, Lee S-M, Lee J-C, Chae PJ, Shea, Byung-Taek Oh (2011) « Monascus Pigment Production by Solid-State Fermentation with Corn Cob Substrate ». J Biosci Bioeng 112(6):590-594. https://doi.org/10.1016/j.jbiosc.2011.08.009

91. Ververis C, Georghiou K, Christodoulakis N, Santas P, Santas R (2004) « Fiber Dimensions, Lignin and Cellulose Content of Various Plant Materials and Their Suitability for Paper Production ». Ind Crops Prod 19(3):245-254. https://doi.org/10.1016/j.indcrop.2003.10.006

92. Guillermo V-DU, Huang T-Y, Chang C-W, Lin H-C, Yen-Ping H (2019) « Fungal Feature Tracker (FFT): A Tool for Quantitatively Characterizing the Morphology and Growth of Filamentous Fungi ». Édité par Timothée Poisot. PLOS Computational Biology 15(10):e1007428. https://doi.org/10.1371/journal.pcbi.1007428

93. Shuangning X, Zhang B, Boakye-Boaten N, and Abolghasem Shahbazi (2017) « Green Biorefinery of Giant Miscanthus for Growing Microalgae and Biofuel Production ». Fermentation 3(4):66. https://doi.org/10.3390/fermentation3040066

94. Xu F, Liu CF, Geng ZC, Sun JX, Sun RC, Hei BH, Lin L, Wu SB, Je J (2006a) « Characterisation of Degraded Organosolv Hemicelluloses from Wheat Straw ». Polym Degrad Stab 91(8):1880-1886. https://doi.org/10.1016/j.polymdegradstab.2005.11.002

95. Xu F, Sun JX, Liu CF, Sun RC (2006b) « Comparative Study of Alkali- and Acidic Organic Solvent-Soluble Hemicellulosic Polysaccharides from Sugarcane Bagasse ». Carbohyd Res 341(2):253-261. https://doi.org/10.1016/j.carres.2005.10.019 
96. Xu Feng J, Yu T, Tesso F, Dowell, Wang D (2013) «Qualitative and Quantitative Analysis of Lignocellulosic Biomass Using Infrared Techniques: A Mini-Review ». Appl Energy 104 (avril):801-809. https://doi.org/10.1016/j.apenergy.2012.12.019

97. Yang Xu X, Ma H, Li J, Chen, and Shuqi Fang (2016) « Effects of Hot-Washing Process on Structure and Enzymatic Hydrolysis of Treated Steam Explosion Corn Stover ». Bioresources Bioprocessing 3(1):39. https://doi.org/10.1186/s40643-016-0115-7

\section{Figures}

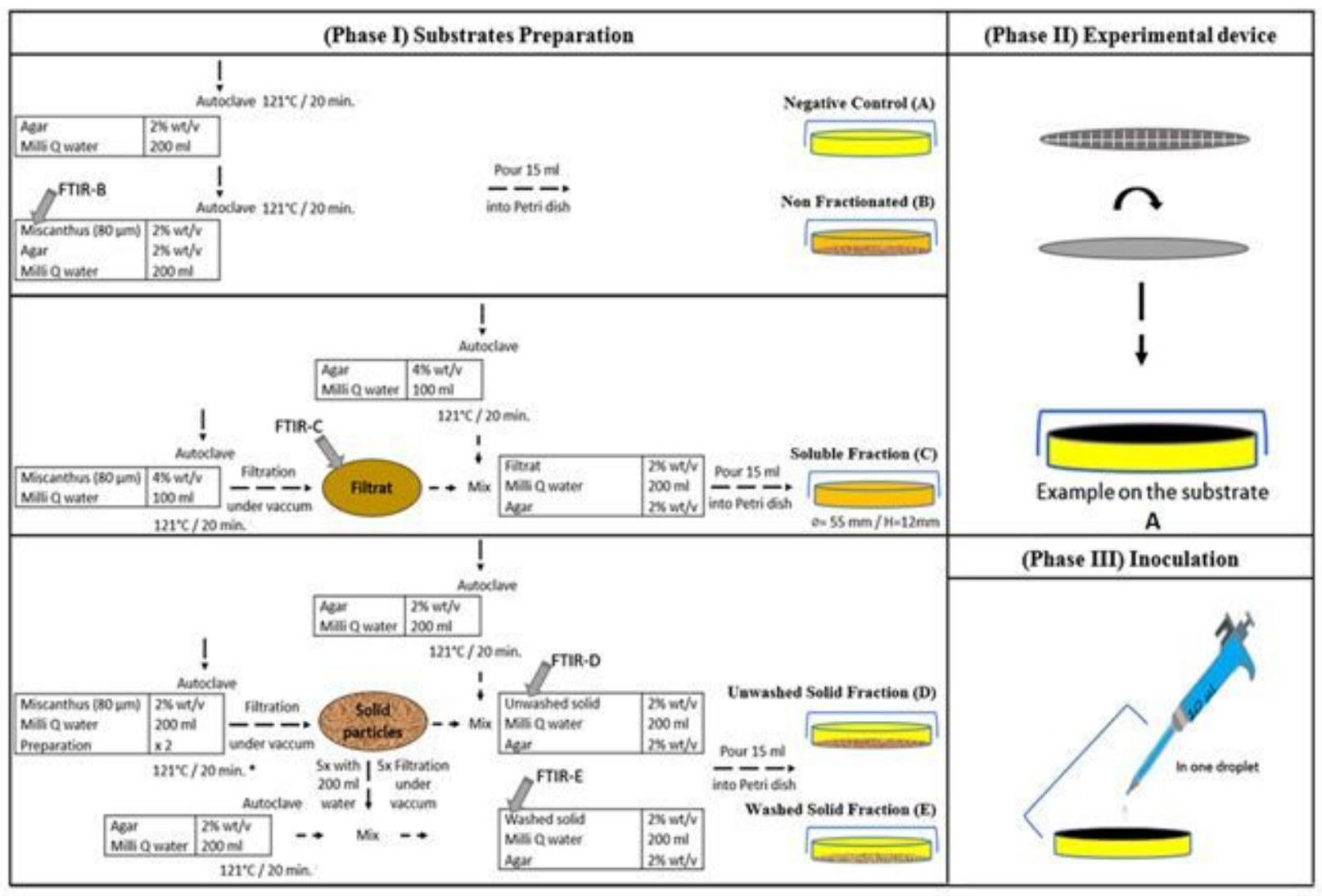

Figure 1

Experimental apparatus and procedure. Phase (I) shows the preparation of all growth media. Phase (II) demonstrates the experimental device. The grey nitrocellulose membrane was placed, grid side down, on the surface of the agar containing different substrates to hide the white lines and provide a homogeneous background for imagery. The preparations were tempered to $70^{\circ} \mathrm{C}$. 


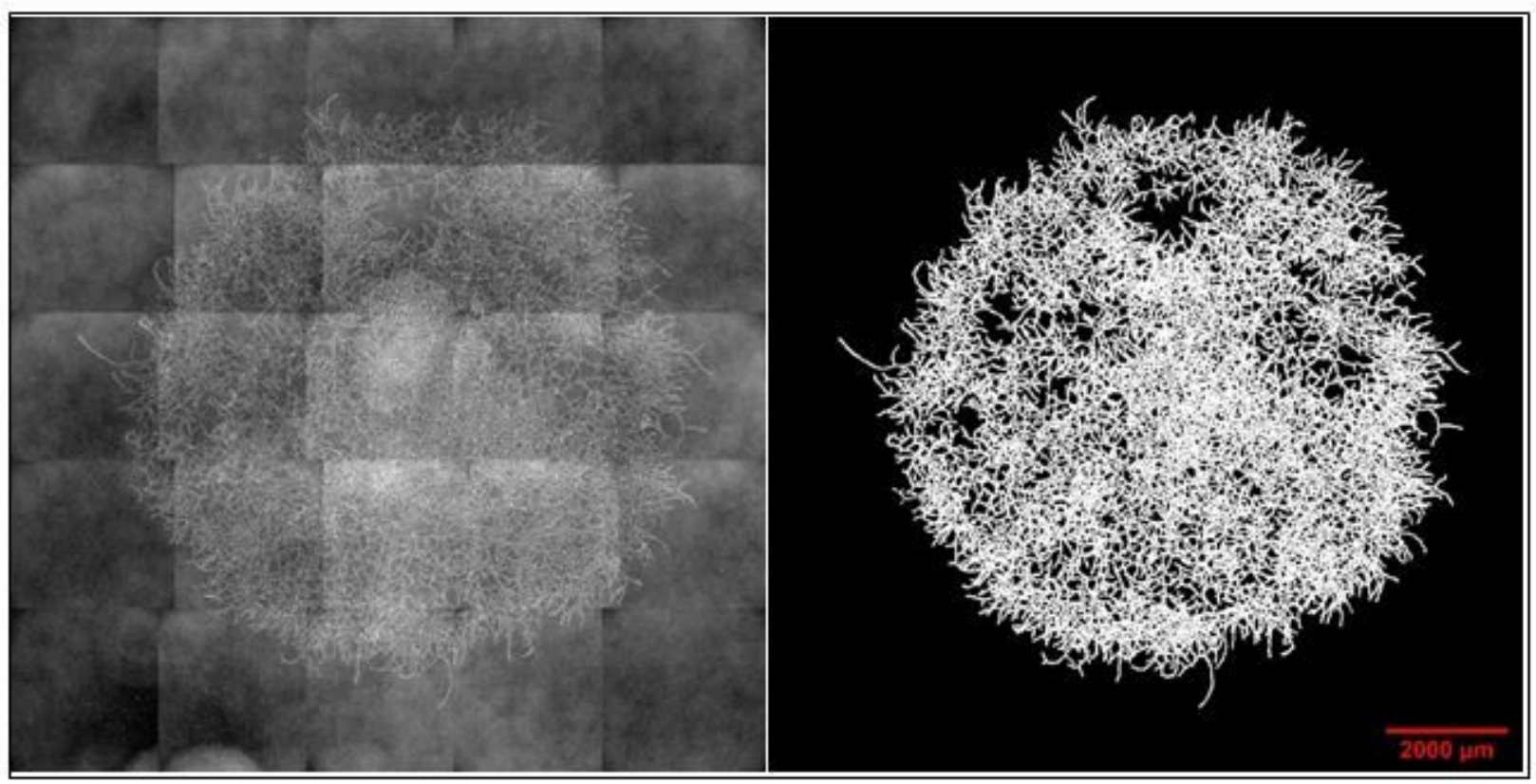

\section{Figure 2}

Example of acquired and processed images of a P. chrysosporium colony. The image acquired after 52 hours of growth on agar medium is on the left. The processed image after image treatment operations (as described in the text) is on the right. Red scale bar $=2000 \mu \mathrm{m}$.

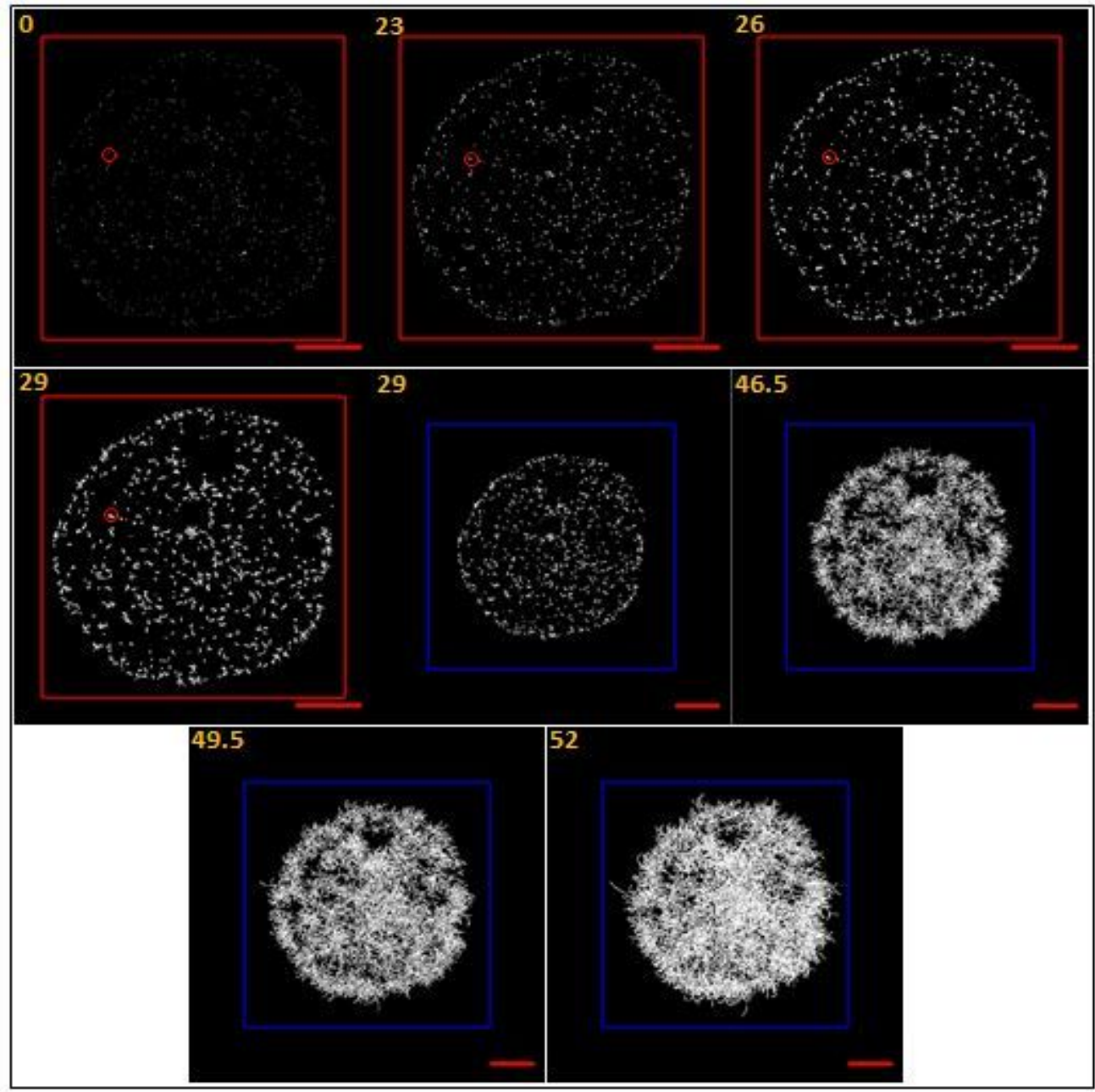




\section{Figure 3}

Germination and growth of P. chrysosporium on agar (defined as negative control - substrate A). Monitoring was performed at 50X magnification. Images show the growth at time $0,23,26,29,46.5,49.5$, and 52 hours. A scale-shift of the image is indicated by the change in the color of the drawn squares from red to blue. The sides of the red square measure $9000 \mu \mathrm{m}$. The length of the sides of the blue squares was $11000 \mu \mathrm{m}$, and the image size is 12288-pixel x 12288-pixel. The red circles show the position of a single spore over time. At 23 hours, the spore was swollen. At 26 hours, a germ tube was formed. A microcolony was observed at 29 hours, where branching started. The final colony can be seen at 52 hours. The red scale bars measure $2000 \mu m$.

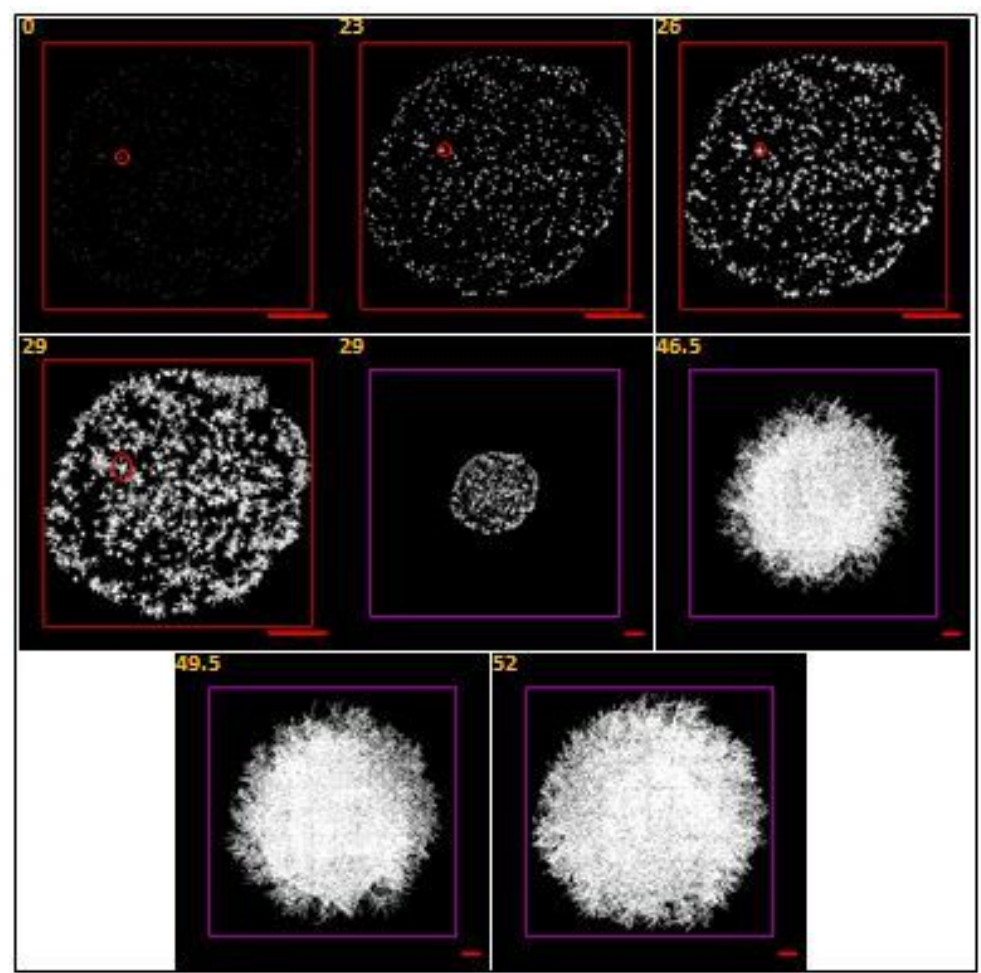

\section{Figure 4}

Germination and growth of P. chrysosporium on the non-fractionated substrate (culture B). The monitoring was performed at 50X magnification. Images show the growth at time 0, 23, 26,29, 46.5, 49.5 and 52 hours. The color change of the square drawn around the colony from red to purple indicates a change in the scale of the image. The sides of the red square measure $9000 \mu \mathrm{m}$. The sides of the purple squares are $25000 \mu \mathrm{m}$ long, and the image size is 24576-pixel x 24576-pixel. The red circles show the position of a single spore over time. At 23 hours, the spore was swollen, and a germ tube was formed. At 26 hours, a microcolony was obtained where branching start to take place. At 29 hours, the amplification of branching continued, and the tips extended, forming bridges with other microcolonies. One colony can be seen at 46.5 hours. The red scale bars measure $2000 \mu \mathrm{m}$. 


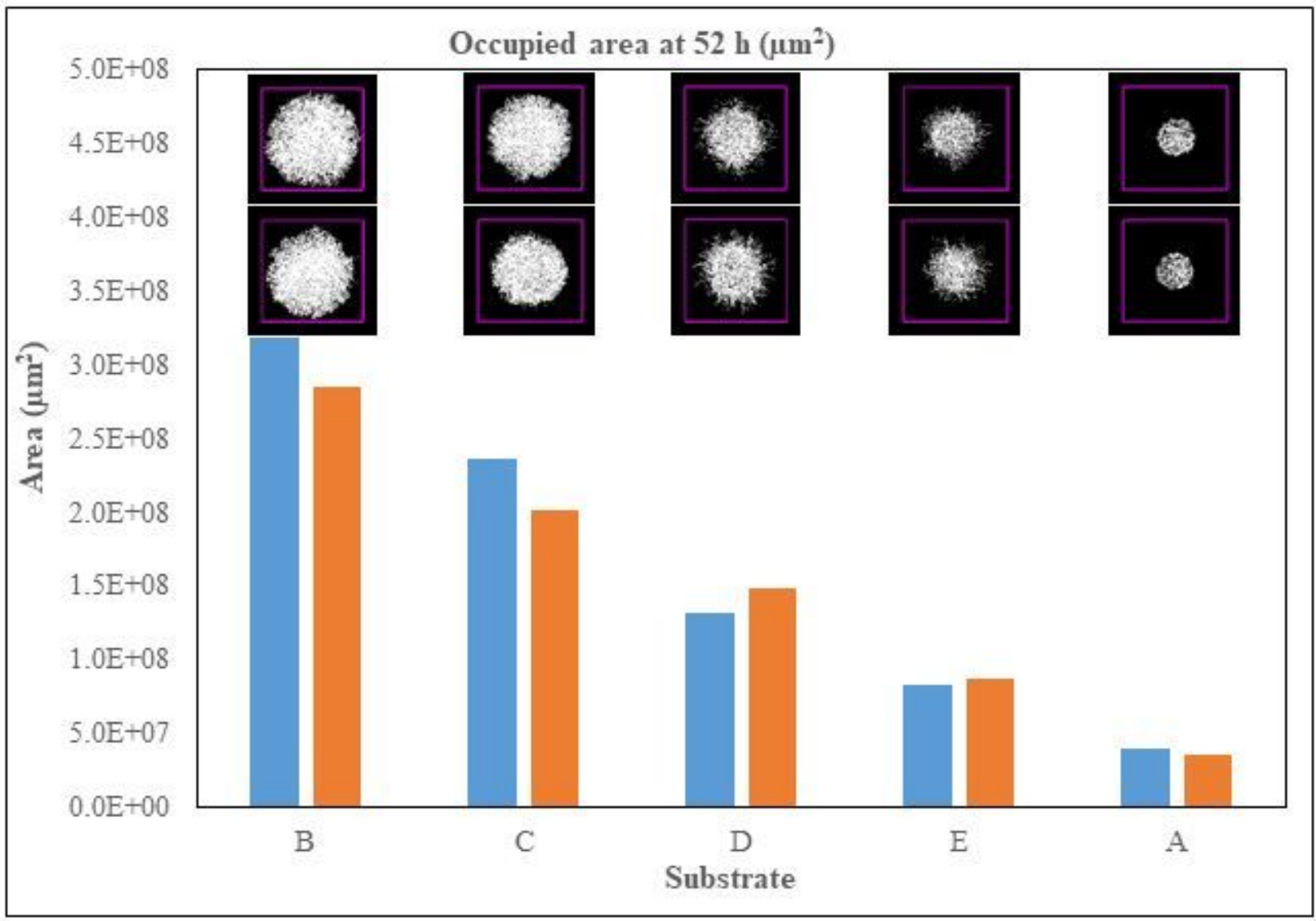

\section{Figure 5}

The area occupied by P. chrysosporium mycelia after 52 hours. The blue and orange bars indicate the data of duplicate cultures for each substrate. The corresponding images visually represent the growth and morphology of the colonies at each time point. The upper row of images corresponds to the data represented by the blue bars, and the lower images correspond to the data represented by the orange bars. Each side of the purple square is $25000 \mu \mathrm{m}$. The mycelium in culture B covered $3.0 \pm 0.2 \times 108 \mu \mathrm{m} 2,8$-fold higher than the negative control (culture $A$ ). At the same time point, culture $C$ was $78 \%$ of culture $B$; culture $D$ was $42 \%$ of culture B, and culture E was $26 \%$ of culture B. The use of non-fractionated miscanthus (Fig. 1) resulted in the fastest growth of the organism followed by the soluble fraction (culture $\mathrm{C}$ ), the unwashed solid fraction (culture D), and the washed solid fraction (culture E). If the growth area on agar alone (culture $A$ ) is subtracted from all growth data, the sum of the growth measured on cultures $C$ and $D$ provided a value close to that of culture $B$. Thus, the covered area on culture $C$ at 52 hours represented $64 \%$ of the covered area of culture $\mathrm{B}$; the soluble fraction is largely responsible for the extent of mycelial growth. 

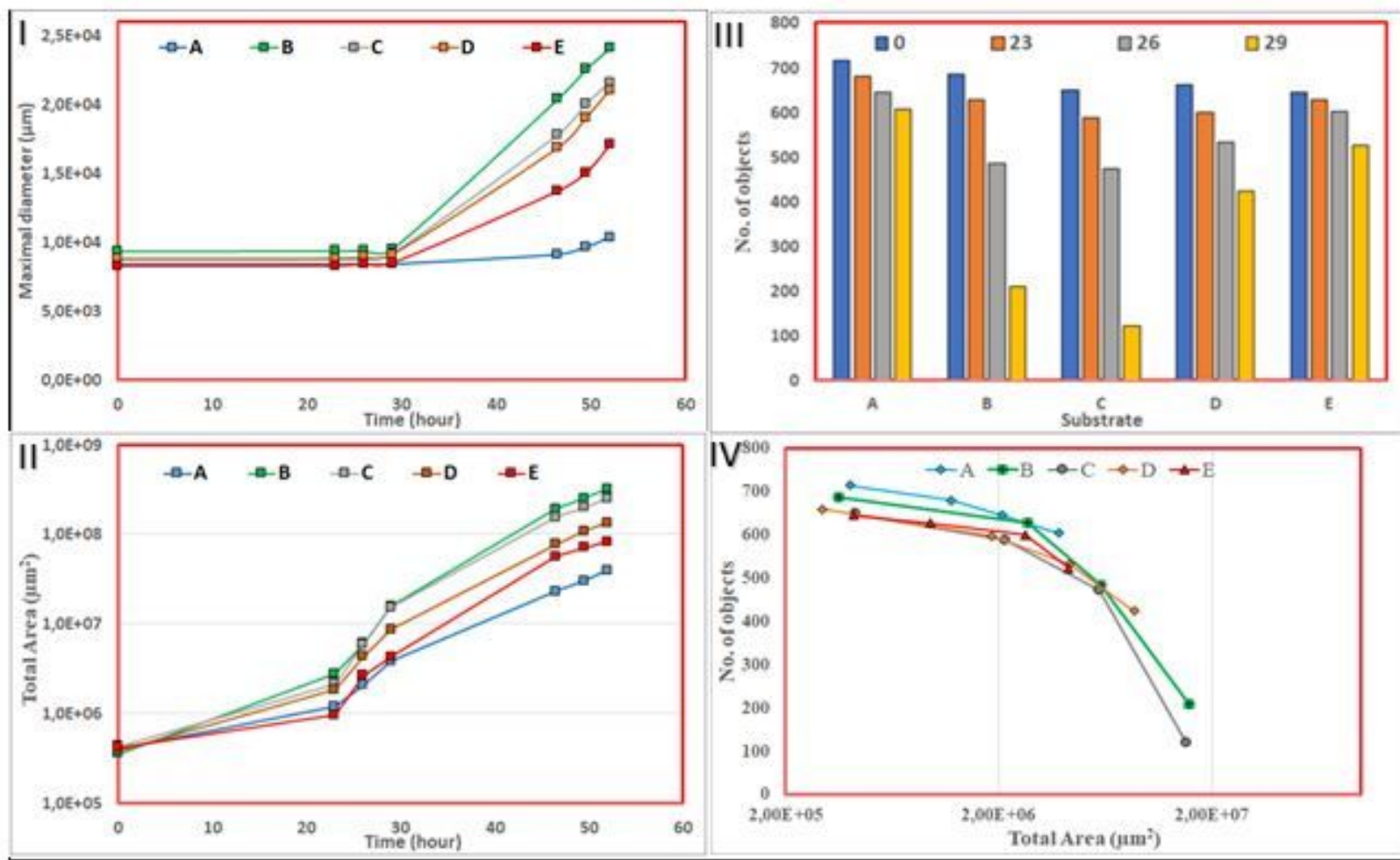

\section{Figure 6}

Three types of measurements describe the growth of P. chrysosporium on different substrates. Graph (I) shows the colony growth measured by radial expansion. Graph (II) shows the colony growth by surface coverage of the membrane by the mycelium. Histograms (III) show the coalescence patterns of objects; each spore is counted as an individual particle at time zero. Graph (IV) shows the number of objects versus the total area occupied by P. chrysosporium. 